\title{
PKR downregulation prevents neurodegeneration and $\beta$-amyloid production in a thiamine-deficient model
}

\author{
F Mouton-Liger, ${ }^{\star, 1,2}$, A-S Rebillat ${ }^{1}$, S Gourmaud ${ }^{1,2}$, C Paquet $^{1,2,3}$, A Leguen ${ }^{1}$, J Dumurgier ${ }^{2,3}$, P Bernadelli ${ }^{4}$, V Taupin ${ }^{4}$, L Pradier ${ }^{4}$, \\ T Rooney ${ }^{4}$ and J Hugon ${ }^{1,2,3}$
}

Brain thiamine homeostasis has an important role in energy metabolism and displays reduced activity in Alzheimer's disease (AD). Thiamine deficiency (TD) induces regionally specific neuronal death in the animal and human brains associated with a mild chronic impairment of oxidative metabolism. These features make the TD model amenable to investigate the cellular mechanisms of neurodegeneration. Once activated by various cellular stresses, including oxidative stress, PKR acts as a pro-apoptotic kinase and negatively controls the protein translation leading to an increase of BACE1 translation. In this study, we used a mouse TD model to assess the involvement of PKR in neuronal death and the molecular mechanisms of AD. Our results showed that the TD model activates the PKR-elF2 $\alpha$ pathway, increases the BACE1 expression levels of A $\beta$ in specific thalamus nuclei and induces motor deficits and neurodegeneration. These effects are reversed by PKR downregulation (using a specific inhibitor or in PKR knockout mice).

Cell Death and Disease (2015) 6, e1594; doi:10.1038/cddis.2014.552; published online 15 January 2015

Thiamine (vitamin B1) deficiency (TD) induces regionally selective neurodegeneration in the mammal's brains, particularly in specific thalamus nuclei (submedial thalamus nuclei (SmTN) and ventral lateral nuclei (VLN)) and cerebellum. ${ }^{1,2}$ TD-induced neuronal loss is associated with a chronic impairment of oxidative metabolism and neuroinflammation associated with glial activation. ${ }^{3-5}$ Diminished thiaminedependent processes in humans is not only associated with Wernicke-Korsakoff syndrome but also accompany other neurodegenerative disorders, such as Alzheimer's disease (AD). ${ }^{6}$ Experimental TD has been used to model the pathogenesis and investigate the cellular mechanisms of neurodegenerative disorders. In mice, TD-induced oxidative stress enhances $A \beta$ accumulation by regulating $\beta$-site APPcleaving enzyme 1 (BACE1) maturation. These effects are amplified in $A D$ mouse model. ${ }^{7,8}$

The double-stranded RNA-dependent protein kinase (PKR) is one of the four mammalian serine-threonine kinases-the others being HRI (heme-regulated eukaryotic translation initiation factor-2a (elF2a) kinase), GCN2 (general control nonderepressible 2) and PERK (protein kinase RNA-like endoplasmic reticulum kinase) - that catalyzes the phosphorylation of the $a$ subunit of elF2 in response to stress signals, leading to an inhibition of protein synthesis. ${ }^{9,10}$ Activation of PKR is induced by various triggers such as viral infection and endoplasmic reticulum or oxidative stresse ${ }^{11,12}$ and could be controlled by an interaction with its specific activator PACT (PKR activator), also named RAX in rodents. PKR phosphorylation is known to have a significant role in $A D,{ }^{13}$ and cerebrospinal fluid (CSF) PKR levels could be used as a potential diagnostic biomarker in AD patients. ${ }^{14,15}$ PKR is a proapoptotic kinase ${ }^{16}$ and can exert a number of toxic effects on neurons that could contribute to the functional and pathological alterations in AD brains. PKR also contributes to neurodegeneration and to the pathological molecular mechanisms observed in AD. PKR can mediate Tau phosphorylation induced by $A \beta$ exposure in cell cultures. ${ }^{17}$ Additionally, several investigators have demonstrated that elF2a phosphorylation, via PKR-induced cellular stress, leads to increased BACE1 mRNA translation when, paradoxically, global protein translation is inhibited. ${ }^{18-21}$ These alterations of BACE1 translational control could be explained by a stressdependent phenomenon of translation initiation. ${ }^{22-24}$ Moreover, PKR and elF2 $a$ are highly phosphorylated in SmTN and the cerebellum of TD mouse model. Analyses performed on cerebellar granule neurons exposed to a thiamine metabolic antagonist suggest that TD-induced neuronal death could be partially mediated by PKR activation. ${ }^{25}$

To date, all studies that have explored the deleterious role of PKR activation in neurodegeneration indicate that inhibition of PKR is a promising approach to inhibit pathological mechanisms. Moreover, recent studies have shown that the genetic lack of PKR enhances learning and memory in several behavioral tasks while increasing network excitability. ${ }^{26}$ The goal of this study was to assess the role of PKR

\footnotetext{
${ }^{1}$ Inserm UMR-S942, Paris 75010, France; ${ }^{2}$ Department of Histology, Pathology and Biochemistry, Saint Louis Lariboisière Fernand Hospital, Service AP-HP, University of Paris Diderot, Paris, France; ${ }^{3}$ Clinical and Research Memory Center, Paris Nord lle de France Saint Louis Lariboisière Fernand Hospital, AP-HP, University of Paris Diderot, Paris, France and ${ }^{4}$ Sanofi-Aventis Therapeutic Strategy Unit Aging, Chilly-Mazarin, France

*Corresponding author: F Mouton-Liger, Inserm UMR-S 942, Groupe Hospitalier St Louis Lariboisière F.Widal. 2, rue Ambroise Paré, Paris 75010, France. Tel: +33 15321 6681; Fax: +33 15321 6739; E-mail: francois.mouton-liger@inserm.fr

Abbreviations: AD, Alzheimer's disease; TD, thiamine deficiency; CSF, cerebrospinal fluid; SmTN, submedial thalamus nuclei; VLN, ventral lateral nuclei; BACE1, $\beta$-site APP-cleaving enzyme 1; PKR, double-stranded RNA-dependent protein kinase; PACT, PKR activator; HRI, heme-regulated elF2 $\alpha$ kinase; GCN2, general control nonderepressible 2; PERK, protein kinase RNA-like endoplasmic reticulum kinase; elF2 $\alpha$, eukaryotic translation initiation factor-2 $\alpha$; MDA, malondialdehyde; NeuN, neuronal nuclei; F-J B, Fluoro-Jade B; IBA1, ionized calcium-binding adaptor molecule 1; APP, amyloid precursor protein

Received 25.8.14; revised 30.10.14; accepted 03.11.14; Edited by A Verkhratsky
} 
downregulation on neurodegeneration and $A \beta$ production in a mouse model of neurodegeneration.

\section{Results}

TD induces regional oxidative stress and inflammation. To assess the consequences of the TD-induced stress cascade in our model, we evaluated the expression of markers of oxidative stress and microglial activation by immunofluorescence in the brain of mice exposed to 10 days of thiamine deprivation (TD mice) compared with wild-type mice (WT). Malondialdehyde (MDA) is the end product of lipid peroxidation and is commonly used as an oxidative stress marker. Using an MDA antibody, immunolabelings in TD mice brain showed a strong increase in staining in the cortical (not shown) and the thalamic neurons (37\% of MDA-positive neurons). In the thalamus, this staining is mainly found in two well-defined thalamic regions (Figure 1a): the SmTN, which is located between bregma levels -0.94 and -1.94 , and the VLN, between bregma levels -0.94 and $-1.94 .{ }^{27} \mathrm{SmTN}$ and VLN exhibit an increase of MDA-positive neurons, $+57 \%$ and $+42 \%$, respectively (Figure 1c). Neurons in WT mice showed weak MDA staining (5.8\% of MDA-positive neurons; Figures $1 \mathrm{~b}$ and $\mathrm{c}$ ). Microglia cells in their inactive state are characterized by a highly branched (ramified) morphology. After activation, they gradually undergo a transition from ramified to round feature (amoeboid). The ratio of these two phenotypical states both stained by an IBA1 antibody (ionized calcium-binding adaptor molecule 1) can be used as an indicator of microglial activation. Quantified immunofluorescence analyses of IBA1-positive microglia (IBA1+) in the thalamus revealed a $247 \%$ increase in the number of amoeboid cells in TD mice compared with controls (Figures $1 \mathrm{~d}$ and $\mathrm{e})$. The percentage of activated microglia was even greater in the SmTN (+343\%) and in the VLN (+289\%) (Figure 1d).

TD enhances PKR activation in the thalamus and cerebellum. To determine whether the inflammatory responses and oxidative stress affect the phosphorylation and expression of PKR in TD mice, immunoblotting with antibodies directed against the threonine (446) phosphorylation site or the total PKR protein were performed in the thalamus, cerebellum, cortex and hippocampus (Figure 2a). Quantification of the a

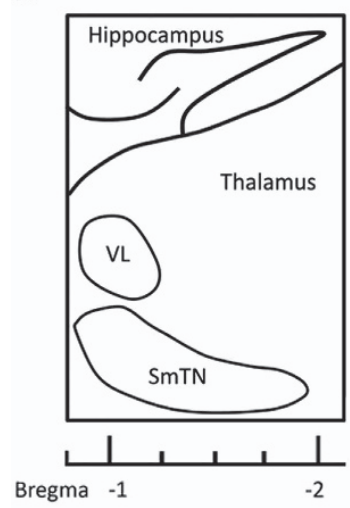

b

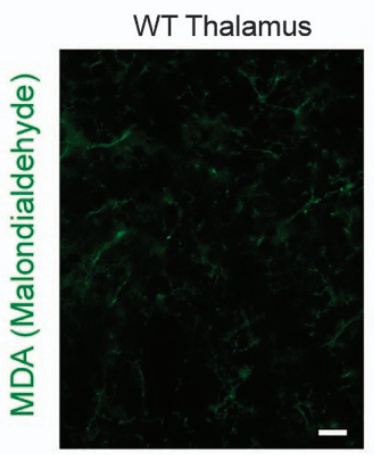

TD Thalamus

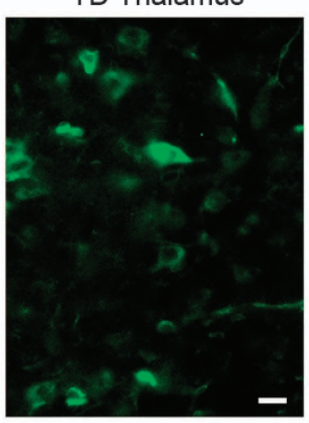

C

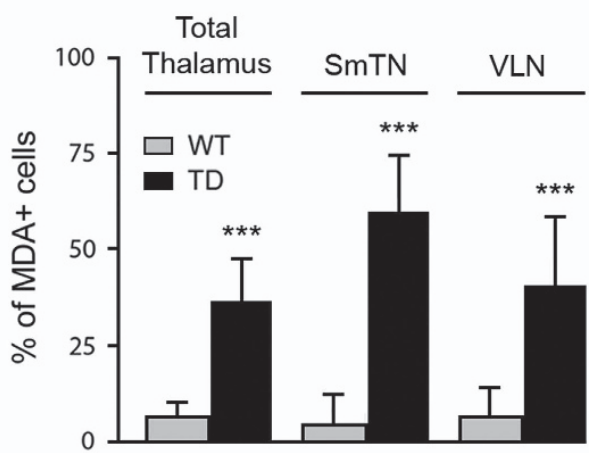

d

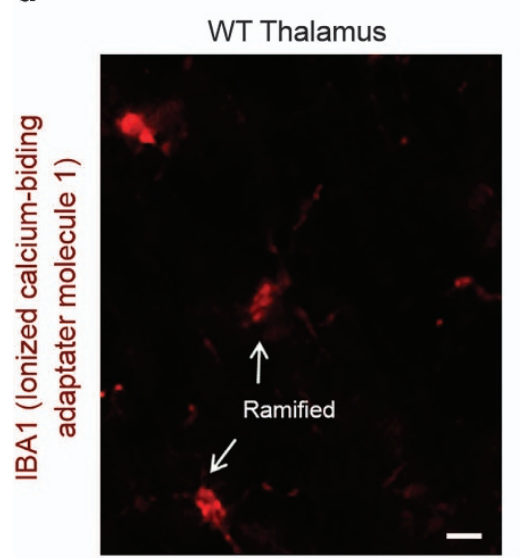

TD Thalamus

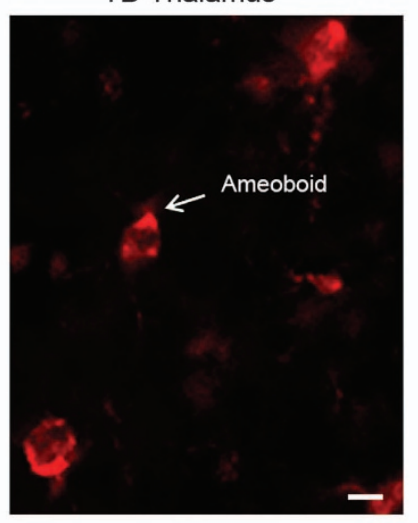

e

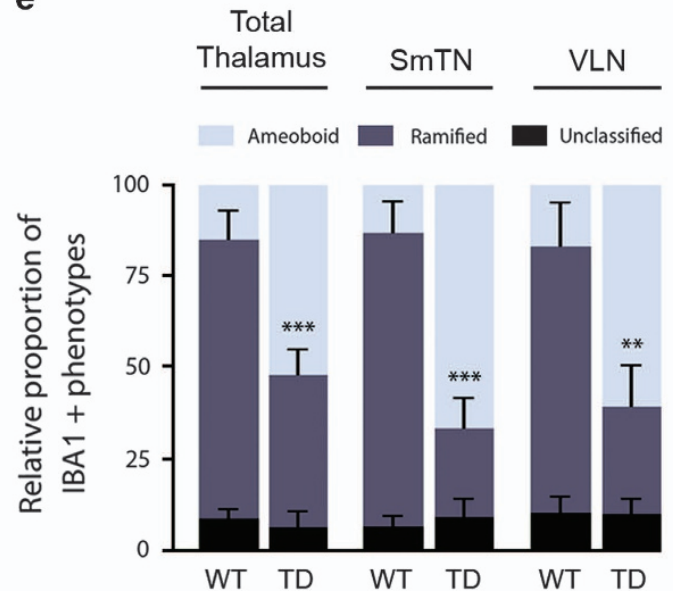

Figure 1 Markers of oxidative stress (MDA) and microglial cell activation (IBA1) in the TD thalamus. (a) Schematic sagittal representation of thalamic nuclei distribution: SmTN; and VLN. (b) MDA immunohistochemistry (green) on the sagittal sections of WTand TD thalamus. (c) Percentage of MDA-positive cells in total thalamus, SmTN and VLN in WT $(n=6)$ and TD mice $(n=6)$. (d) IBA1 labeling (red) on the sagittal sections of WT and TD thalamus. (e) Quantification of relative proportion of IBA1-positive microglial cell phenotypes: ramified shape (inactivated state) and amoeboid shape (activated state) in WT $(n=7)$ and TD mice $(n=7)$. Unclassified shape corresponds to intermediate state or cells that were unable to be quantified. Scale bars: $10 \mu \mathrm{m} .{ }^{* *} P<0.01,{ }^{* \star *} P<0.001$ 
$\mathrm{pPKR}_{\text {Thr446 }} / \mathrm{PKR}$ ratio showed a strong increase after TD in the thalamus, cerebellum and cortex of 139, 95 and $43 \%$, respectively (Figure $2 \mathrm{~b}$ ). By contrast, there was no significant change in pPKR in the hippocampus (Figure 2b).

To explore the signaling pathway at the origin of PKR activation in TD, we performed immunoblots of the PKR main stress-dependent inducer, RAX, and the data revealed a significant increase in RAX in the thalamus and cerebellum (Supplementary Figure S1).

a

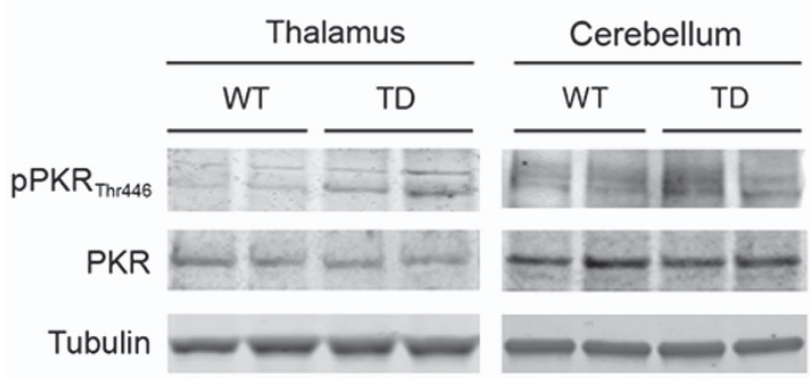

C

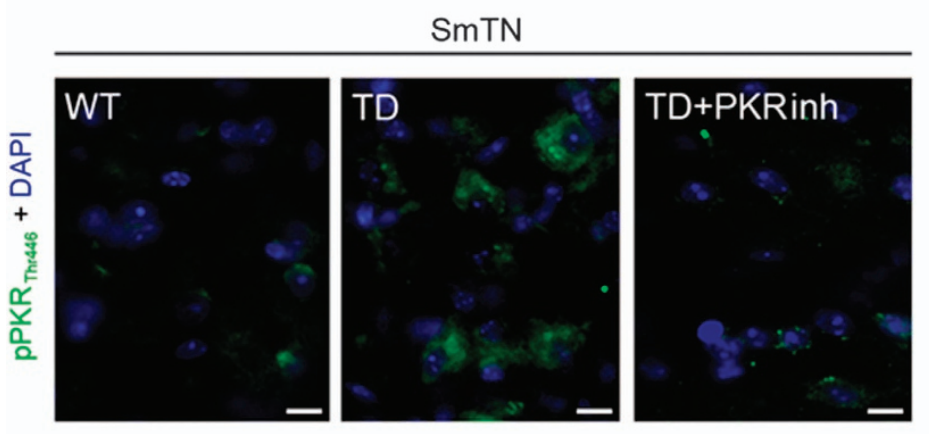

e

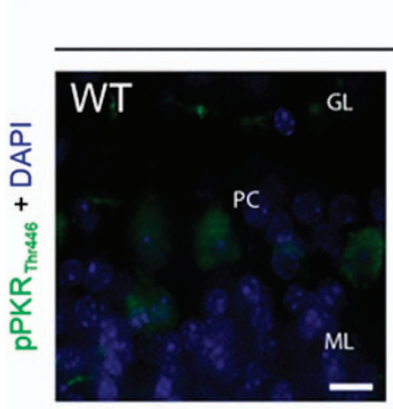

Cerebellum
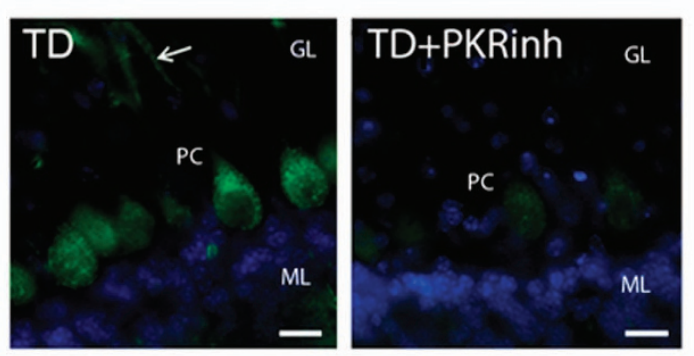

PKR knockout $\left(\mathrm{PKR}^{-1-}\right)$ mice are viable, phenotypically indistinguishable from their wild type ${ }^{28}$ and have been used in several studies to test the protective role of PKR. ${ }^{26,29}$ As expected, we did not detect a 65-kDa PKR band in brain samples of $\mathrm{PKR}^{-1-}$ mice (Supplementary Figure S2). We extended the above TD findings by counting $\mathrm{PPKR}_{\text {Thr446- }}$ positive immunoreactive cells in the whole thalamus and in specific nuclei in the SmTN and VLN known to be more strongly affected by TD (Figures $2 c$ and $d$ ) in animals

b

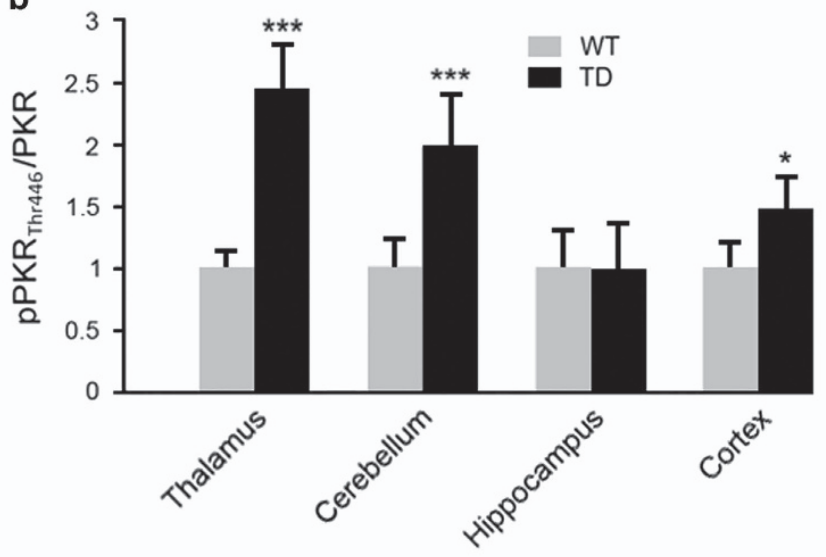

d

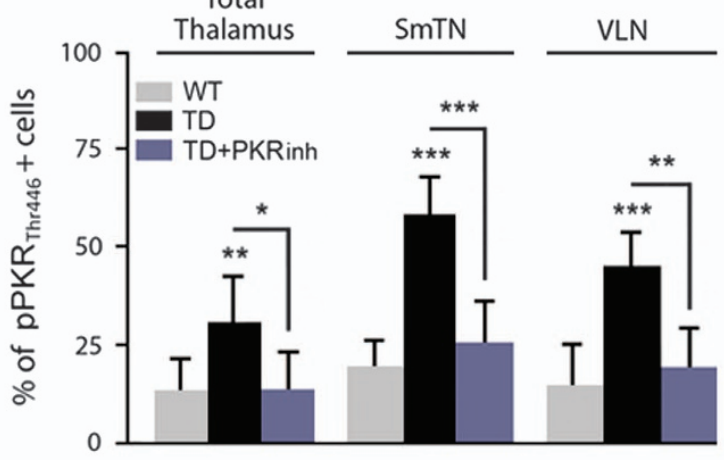

f

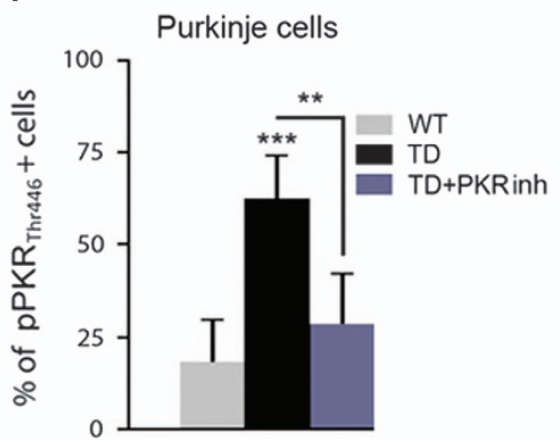

Figure 2 Activation of PKR in TD brain studied by immunoblotting and immunohistochemistry in the thalamus and cerebellum. Immunoblot analyses (a) and corresponding

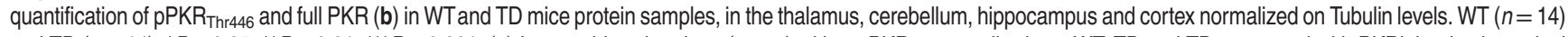
and TD $(n=14) .{ }^{*} P<0.05,{ }^{\star *} P<0.01,{ }^{* \star} P<0.001$. (c) Immunohistochemistry (green) with a PPKR ${ }_{\text {Thr446 }}$ antibody on WT, TD and TD pretreated with PKRinh mice in sagittal sections of (c) SmTN and (e) cerebellum. (d) The positive cell counting confirmed that PKR is activated after TD treatment and its increase is attenuated by PKRinh administration in total thalamus, specifically in SmTN and VLN. (e) Cerebellar PPKR Thr446 patterns in WT, TD and TD+PKRinh. PPKR Thr446 staining is almost absent in granular layer (GL) and molecular layer (ML) but exhibits strong signals and increased after TD in Purkinje cells (PC), both in cell bodies and processes (arrow). (f) The percentages of PC with $\mathrm{pPKR}_{\text {Thr446 }}$ nuclear localization have been quantified, and as expected, $\mathrm{PPKR}_{\text {Thr } 446}$ staining is decreased in PC after PKRinh administration WT $(n=8)$ and TD $(n=8)$. Scale bars: $10 \mu \mathrm{m}$ 
pretreated $(30 \mathrm{mg} / \mathrm{kg}$ per os) or not with a PKR inhibitor (PKRinh) provided by Sanofi. There was a significant enhancement of $p P K R_{\text {Thr446 }}$ expression after TD exposure. This effect was decreased after PKRinh pretreatment $(-51 \%$ in total thalamus, $-52 \%$ in SmTN, $-54 \%$ in VLN) (Figure 2d) were observed in both structures. A comparable TD-induced increase of $\mathrm{pPKR} \mathrm{R}_{\mathrm{Th} 446}$ staining was detected in the cerebellum where pPKR $\mathrm{Thr}_{\text {Th4 }}$ is mostly present in Purkinje cell bodies and their arborizations (arrows) (+192\%) (Figures $2 e$ and f). In TD mice pretreated with PKRinh, the number of PKR-positive neurons was significantly reduced (58.9\%; Figure $2 \mathrm{f})$.

PKR inhibition reduces elF2 $\boldsymbol{a}$ activation in TD. To test whether TD-induced PKR activation could control elF2a phosphorylation, we performed immunoblot analyses in mice pretreated or not with PKRinh or in $\mathrm{PKR}^{-1-}$ mice. PKRinh inhibits elF2 $a$ phosphorylation in the thalamus $(-31 \%)$ and cerebellum (-39\%) (Figures $3 a$ and b). After genetic knockdown of PKR, TD-elF2a activation was also reduced (Figure 3b). Quantified immunofluorescence of pelF2 $a_{\text {Ser51- }}$ positive neurons has confirmed these effects in the studied structures (Figures $4 \mathrm{a}$ and b). We also found that immunostaining for pelF $2 a_{\text {Ser51 }}$ has a neuronal localization in the thalamus in the ventral posterolateral nucleus (VPL), with the strongest labeling in the SmTN and to a lesser extent in the VLN (Figure 4c).

In the cerebellum, TD-dependant activation of pelF2 $a_{\text {Ser51 }}$ was predominantly observed in cell bodies and processes of Purkinje cells. As expected, pelF $2 a_{\text {Ser51 }}$ staining is reduced by downregulation or inhibition of PKR (Figures $4 b$ and $d$ ). The expression of pelF2 $a_{\text {Ser51 }}$ signals showed a high degree of colocalization with $\mathrm{pPKR}_{\mathrm{Thr} 446}$ staining in the thalamus (not shown) and in cerebellar Purkinje cells (Figure 4e). An increased elF2a phosphorylation was also detected by immunoblot or immunofluorescence in cortical structures (Supplementary Figures S3a and b) but not in the hippocampus (Supplementary Figure S3a). Of the four known elF2a kinases, the most likely to be induced by vitamin B1 deficiency is PKR. Therefore we tried to determine whether PERK, activated by the ER stress/unfolded protein response, GCN2 and HRI could contribute to TD-elF2 $a$ activation. Immunoblots of the thalamus, cerebellum and hippocampus samples from TD and control mice did not reveal any statistically significant variations of the $\mathrm{pPERK}_{\text {Thr980}} / \mathrm{PERK}$ ratio and $\mathrm{HRI}$ levels (Supplementary Figures S3c and d). However, we observed a $38.3 \%$ increase $(P=0.044)$ of $\mathrm{pGCN} 2_{\text {Thr899 }} / \mathrm{GCN} 2$ ratio in the compared with control (Supplementary Figure S3e).

PKR inhibition reduces neuronal loss and neurodegeneration owing to TD. The neuronal nuclei (NeuN) antigen was used as a specific neuronal marker to quantify neuronal cell loss under various pathological conditions. Cell counting of NeuN-positive neurons in TD and control mice did not reveal any significant decrease in the various brain areas evaluated: cortex, cerebellum, hippocampus, and thalamus (data not shown). However, the evaluation in two specific thalamus nuclei (Figure 5a), SmTN and VLN, displayed a significant decrease of neuron density (54 and $37 \%$, respectively) (Figure $5 \mathrm{~b}$ ). The pretreatment of mice with PKRinh before TD induction or TD context in knockdown
PKR $\left(\mathrm{PKR}^{-/-}\right)$significantly reduced neuronal loss observed in the TD-SmTN $(-73 \%)$. Similar protective effect have been found by pretreating TD mice with PKRinh in SmTN (-42\%) and VLN $(-39 \%)$. We then investigated the presence of damaged neurons in different thalamic areas using FluoroJade $B(F-J B)$, an anionic fluorescein derivative that has been reported to specifically stain degenerating neurons. As expected, we did not detect any staining in $\mathrm{Wt}$ mice (Figure $5 \mathrm{c}$ ). In the TD thalamus, $97 \%$ of F-J B+cells were present in the SmTN or VLN. PKR inhibition did not affect the total number of F-J B-stained cells (Figure $5 \mathrm{~d}$ ). To take into account the decreased neuronal density owing to TD, we have adjusted the number of F-J B-positive neurons to the total number of neurons counted in Figure 5b. Downregulation of PKR significantly reduced the number of damaged neurons in TD SmTN (-62\%) and VLN (-46\%). Similar results were obtained in TD mice pretreated with PKRinh (57 and 30\%, respectively) (Figure 5e).

On the contrary, we did not observe any effect of PKR inhibition on oxidative stress (Supplementary Figure S4) or microglial activation (Supplementary Figure S5). In summary, PKR inhibition prevents neuronal loss induced by TD but has no effect on TD-induced oxidative stress or neuroinflammation.

Finally, to determine whether TD could lead to caspase 3mediated apoptosis mainly in the SmTN, we quantified the number of neurons positive for a cleaved-caspase 3 antibody (Figure 6a). There was a large increase in apoptosis (+98\% of positive cells) in the SmTN (Figure 6b). In addition, cleavedcaspase 3 stainings was also increased in TD Purkinje cells ( $+46 \%$ of positive cells) (Figures $7 d$ and e). Interestingly, cleaved-caspase 3 and pPKR $\mathrm{Thr}_{\text {Th46 }}$ staining showed a high degree of colocalization in the SmTN (Figure 6c) and cerebellum (not shown). Inhibition of PKR, either by PKRinh or in $\mathrm{PKR}^{-1-}$ mice, significantly reduced $\mathrm{TD}$-induced caspase 3 levels in SmTN neurons (35 and 44\%, respectively) (Figure $6 b$ ) but not in Purkinje cells (Figures $6 \mathrm{~d}$ and e).

PKR downregulation inhibited amyloidogenic amyloid precursor protein (APP) processing in vivo and $A \beta$ production. Previous studies have shown that PKRinduced elF2a phosphorylation could increase BACE1 translation. ${ }^{18,19}$ To evaluate the functional importance of the PKR-elF2 $a$ pathway in amyloidogenic signaling in TD mice, APP processing was assessed by immunoblotting of APP, BACE1 mature form and amyloid oligomers (Figure 7a). Quantified immunoblot demonstrated that BACE1 protein and amyloid $\beta$ levels are significantly increased in the TD thalamus (by 110 and 52\%, respectively) (Figures $7 \mathrm{~b}$ and d). The TD-induced $A \beta$ increase was confirmed by using ELISA assay for soluble $A \beta$ (Figure 7e). By contrast, there were no changes in mRNA levels of BACE1 measured by real-time quantitative PCR (Figure 7c) or in APP protein expression in TD mice compared with control mice (Figure 7f). After 10 days of TD, $\mathrm{PKR}^{-1-}$ and PKRinh pretreated mice both exhibit a significantly reduced levels of $A \beta$ levels in the thalamus ( -39 and $-33 \%)$. In summary, PKR blockade attenuates $A \beta$ levels in TD mice.

We also investigated a potential role of PKR downregulation on Tau hyperphosphorylation by quantifying the levels of pTau on three hyperphosphorylated sites (AT8, AT100 and AT180) 
a

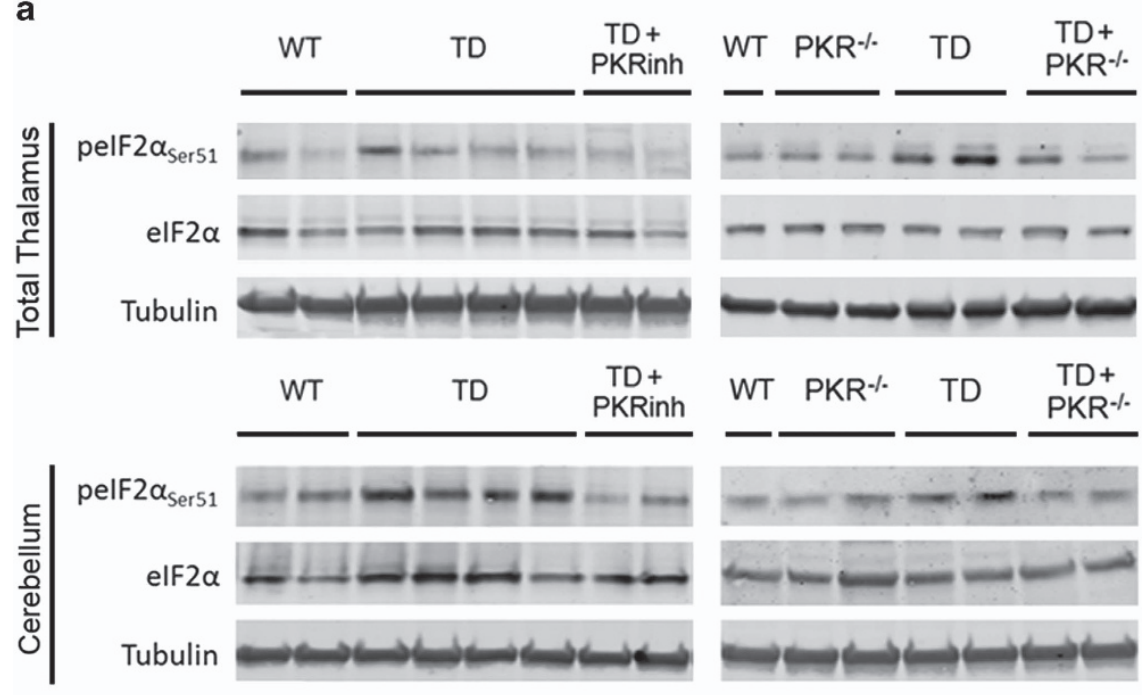

b

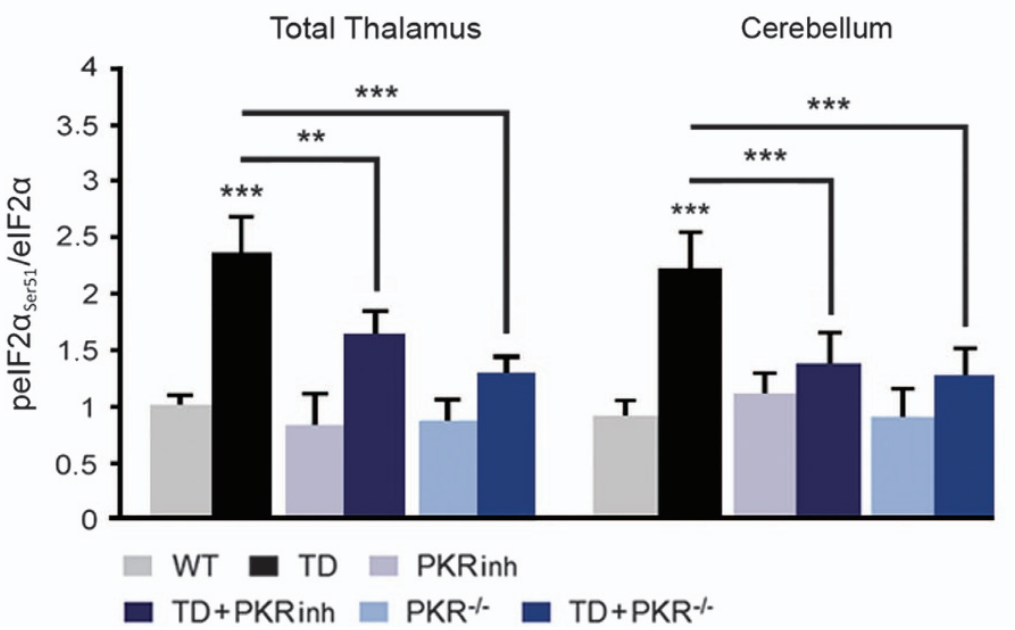

Figure 3 PKR inhibition controls elF2 $\alpha$ activity in TD mouse thalamic and cerebellar neurons. (a and $\mathbf{b})$ Immunoblot analyses (a) and corresponding quantification (b) after normalization on Tubulin of pelF2 $\alpha_{\text {Ser51 }} / \mathrm{elF} 2 \alpha$ ratios in the three groups of mice non-exposed to TD (WT $(n=14)$, PKRinh $(n=10)$ and TD+PKR $\left.{ }^{-1-}(n=12)\right)$ and in the three groups of vitamin B1-deficient mice (TD $(n=14)$, TD+PKRinh $(n=10)$ and TD+PKR $\left.{ }^{-l-}(n=12)\right)$ in the total thalamus and cerebellum

and of two kinases, JNK and GSK-3 $\beta$, known to phosphorylate Tau in stress conditions. Comparisons of TD with control mice did not reveal any difference in AT100, AT180, GSK-3 $\beta$ and JNK activation ratio (Supplementary Figure S6).

Decreasing PKR activation mitigates motor deficits. Marked motor deficits have already been described in several TD models. ${ }^{30}$ We therefore assessed motor coordination and balance in our TD mice using a rotarod apparatus (Figure 8a). Analyses of latency to fall in TD and control mice on an accelerating rotarod revealed a significant progressive decline of motor performance from day 8 in TD mice (Figure 8b). PKR downregulation, either by PKRinh administration or by using $\mathrm{PKR}^{-/}$mice, significantly reduced motor decline at day 8 in TD mice (Figure 8b). After 10 days, motor performance scores of deficient mice were strongly impaired and were not modified by PKR inhibition. Rotarod results of TD mice have to be related to the general status of the mice, as evaluated in this study by body weight measurement (Supplementary Figure S7). In comparison to non-deficient mice, TD mice exhibit a dramatic weight loss starting at day 8 that is not reduced by PKR inhibition. Finally, we also measured $\mathrm{pPKR}_{\mathrm{Thr} 446}$ and pelF $2 a_{\text {Ser51 }}$ in the gastrocnemius muscle in order to evaluate a role of PKRelF2a pathway inhibition in the muscle. Immunoblot analyses did not reveal any variation in the phosphorylation ratios of these two proteins (Supplementary Figure S8).

\section{Discussion}

In the present study, we provide experimental data supporting the concept that 'in vivo' inhibition of the double-stranded RNA activated protein kinase PKR, originally identified as a sensor of virus infection, ${ }^{31}$ has a neuroprotective action and can decrease $\mathrm{A} \beta$ production in a mouse model of neurodegeneration.

TD induces a strong increase of brain PKR activation, particularly in the thalamus and cerebellum. These observations are consistent with the previous study of Wang et al., ${ }^{25}$ which showed a progressive increase of PKR phosphorylation 


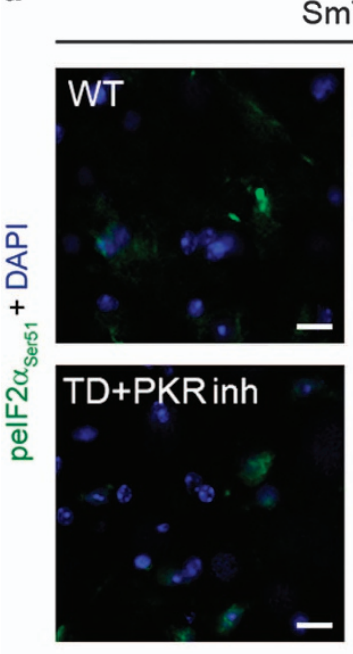

C

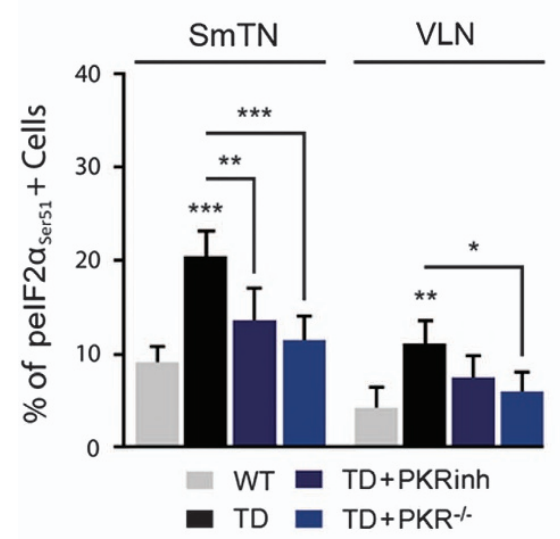

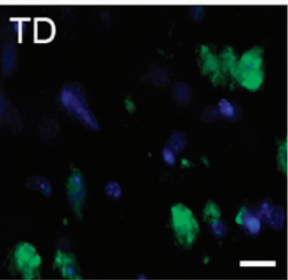

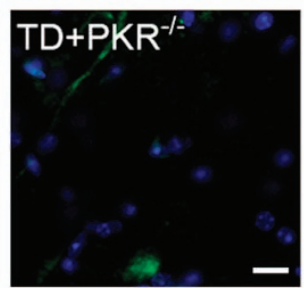

d b

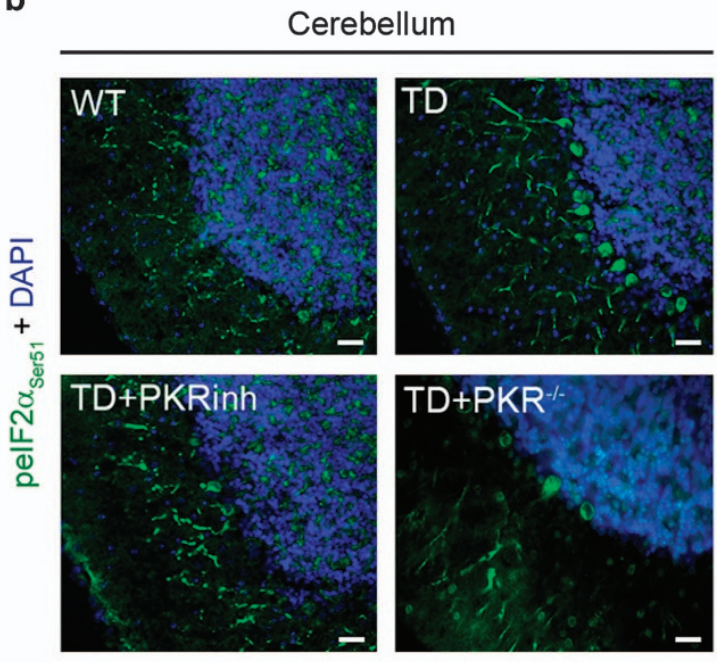

e

Purkinje cells
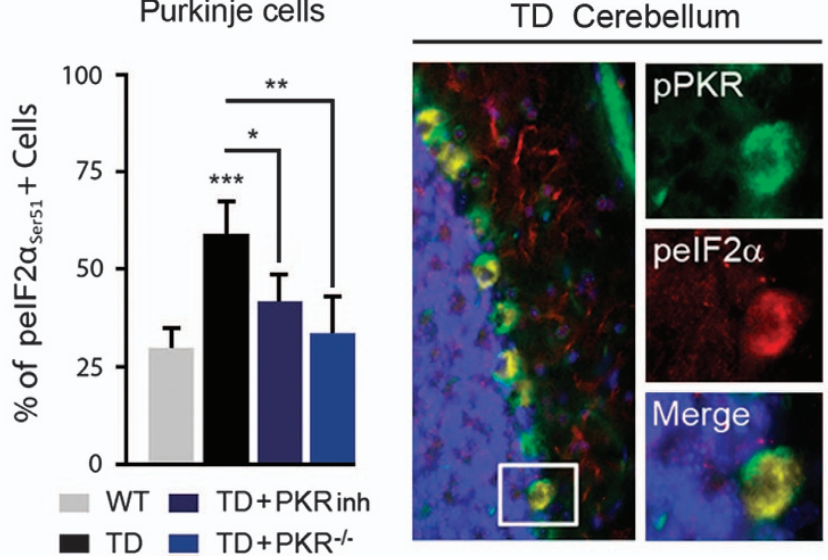

Figure 4 elF2 $\alpha_{\text {Ser51 }}$ cellular localization in the thalamus and cerebellum in TD mice. (a and $\left.\mathbf{b}\right)$ Double-labeling of DAPI (4,6-diamidino-2-phenylindole; blue) and pelF2 $\alpha_{\text {Ser51 }}$ (green) in the (a) SmTN and (b) cerebellum of WT, TD, TD+PKRinh and TD+PKR ${ }^{-1}-$ mice. pelF2 $\alpha_{\text {Ser5 } 1}$ in cerebellum is present in Purkinje cells' cytoplasm and mainly increase after TD at the level of the cells bodies. Scale bars: $10 \mu \mathrm{m}$. (c and d) Quantification of positive neurons in SmTN and (c) VLN and (d) in Purkinje cells suggests that pelF2 $\alpha_{\text {Ser51 }}$ phosphorylation is dependent of $p P K R_{\text {Thr } 446}$ activation. ${ }^{*} P<0.05,{ }^{\star \star} P<0.01,{ }^{* \star *} P<0.001$. (e) Confocal analysis showed a colocalization of $p P K R_{\text {Thr } 446}$ (green) and pelF2 $\alpha$ (red) in TD cerebellum of the cerebellum. Boxes represent higher magnification at the level of Purkinje cells, where colocalization (yellow) is mainly present in cell bodies

on threonine 446 and 451 , in these two structures, from the fifth day of TD. In our work, we have described the histological localization of $\mathrm{pPKR}$ Thr446 overexpression in TD brain. In the thalamus, TD-induced, PKR activation is mainly detected in the submedial and ventrolateral nuclei, which are also the brain areas most strongly affected by oxidative stress and inflammation. The expression of activated PKR in the cerebellum is mainly in the Purkinje layer that is partly comparable to the findings described by our group in the human brain affected by prion diseases that can trigger PKR activation. $^{32}$ This expression pattern is also in line with the PKR mRNA profile visible on the Allen Brain Atlas, which shows a strong expression in Purkinje cells. Additionally, it is known that PACT, or its murine counterpart RAX, is responsible for cellular PKR activation in response to a variety of extracellular stresses. ${ }^{33,34}$ After ethanol exposure, which shares common features with TD, RAX protein located in Purkinje layer interacts with $\mathrm{PKR}$ to reduce neuronal survival. ${ }^{35}$ After TD, we have also observed a significant increase of RAX levels in the cerebellum and at a lower magnitude in the thalamus, suggesting that RAX could mediate PKR activation in this TD cerebellum.

In vivo inhibition of PKR has been recently shown to exhibit significant positive effects such as enhancing memory and learning in behavioral tasks while increasing network excitability ${ }^{26,36-38}$ and protecting animals from high-fat dietinduced insulin resistance and glucose intolerance. ${ }^{29}$ Previous studies in neuronal cultures have shown that PKR inhibition can attenuate neuronal death induced by various stresses, including $A \beta$ neurotoxicity. ${ }^{39,40}$ In the present study, we used a well-described PKR knockout model ${ }^{28}$ and a selective inhibitor of PKR activation (provided by Sanofi) to further evaluate the role of PKR in neurodegeneration in vivo. One of the major findings of this work is the validation that PKR inhibition can protect against neuronal loss in a model characterized by oxidative stress and neuroinflammation. Both stresses have been previously linked to PKR activation. ${ }^{41,42}$ We demonstrated here that they act upstream 


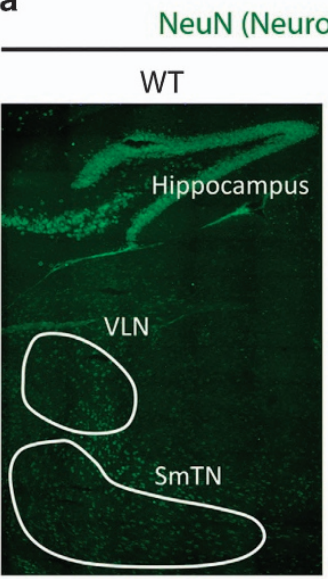

b

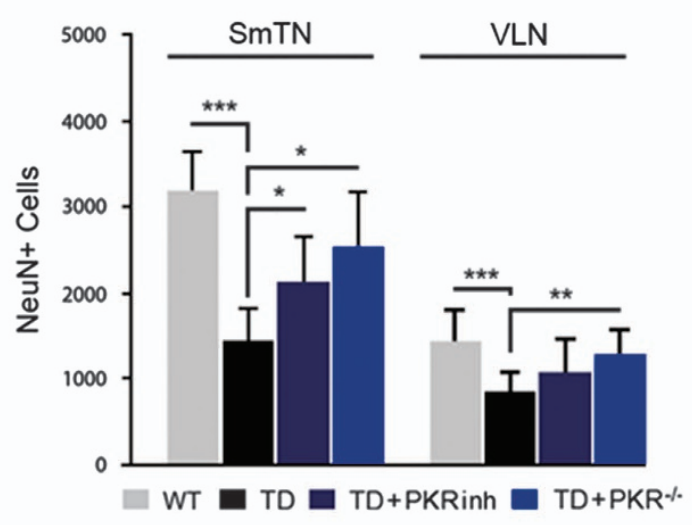

C

Fluorojade B

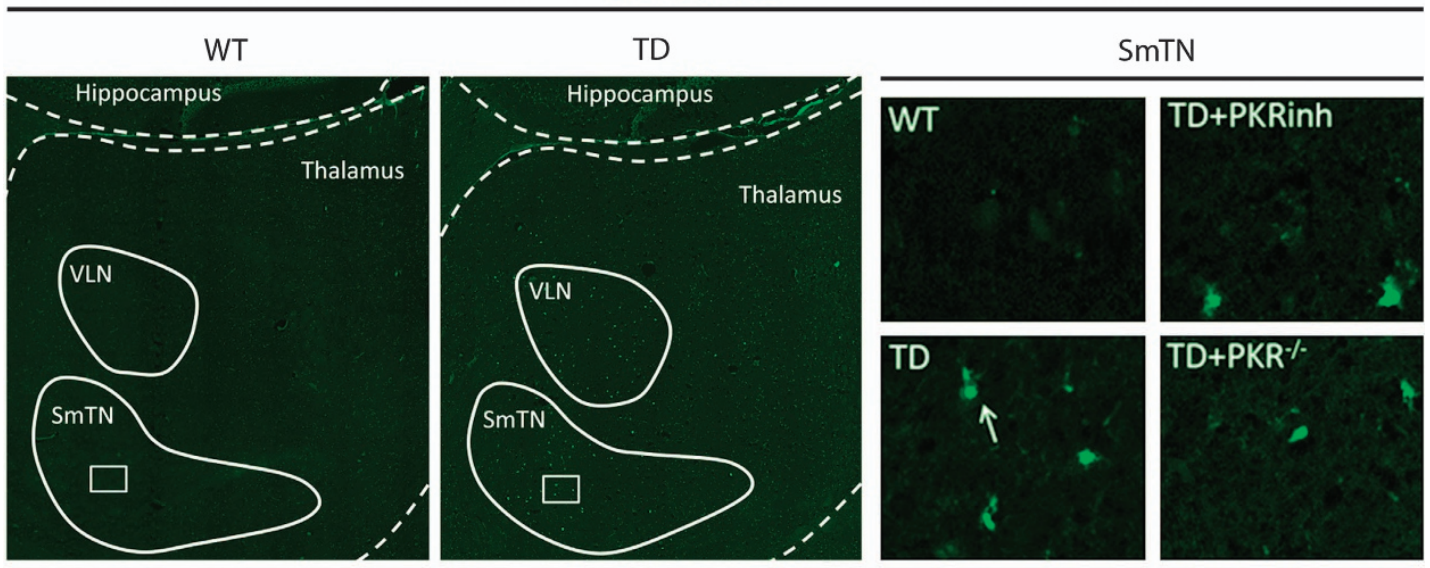

d

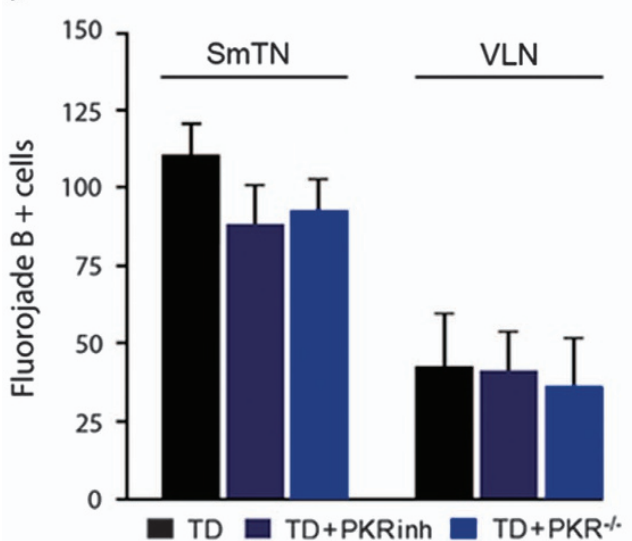

e

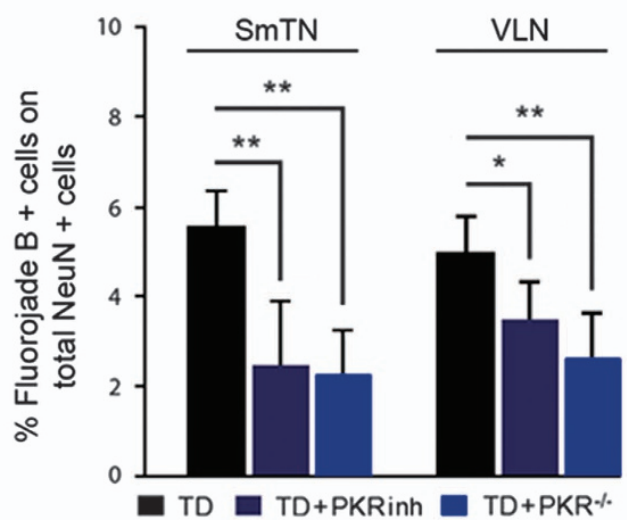

Figure 5 Regional TD-induced neuronal loss and neurodegeneration in the thalamus reduced by modulation of PKR activation. (a) Immunohistochemistry of neuronal nuclear marker NeuN (green) shows a decreased number of neuron in the TD thalamus compared with control mice, in particular in SmTN and VLN (surrounded areas). (b) The number of marked NeuN cells' evaluation indicates that TD-induced neuronal loss is reversed by PKR inhibition in the SmTN and in VLN. WT $(n=8)$, TD $(n=8)$ TD+PKRinh $(n=8)$ and TD+PKR ${ }^{-1-}(n=7)$. (c) F-J B histofluorescence in thalamic regions (surrounded nuclei: SmTN and VLN) reveals, as visible in higher magnification boxes, neurodegenerative neurons in TD mice. Note that WT thalamus did not present a positive signal. (d and e) Relative analysis as number of F-J B+ cells in SmTN and VLN (d) or the percent normalized on the mean number of $\mathrm{NeuN}_{+}(\mathrm{e})$. The percentage of TD-damaged neurons is decreased by PKR inhibition $\left(T D+P K R i n h\right.$ and TD+PKR $\left.{ }^{-1-}\right)$. WT $(n=8)$, TD $(n=8)$ TD+PKRinh $(n=8)$ and TD+PKR ${ }^{-l-}(n=7) ;{ }^{*} P<0.05,{ }^{* *} P<0.01,{ }^{* * *} P<0.001$

of PKR-elF2a pathway activation. However, these results did not allow us, at this stage, to determine the respective role in the TD model of neuroinflammation and oxidative stress in PKR activation.
Thalamic regional neuronal loss in TD rodents was described several times by the group of Gibson. ${ }^{43-45}$ Nonetheless, the cellular mechanisms underlying this neuronal loss are not fully understood. One of the major hypotheses to consider is the 


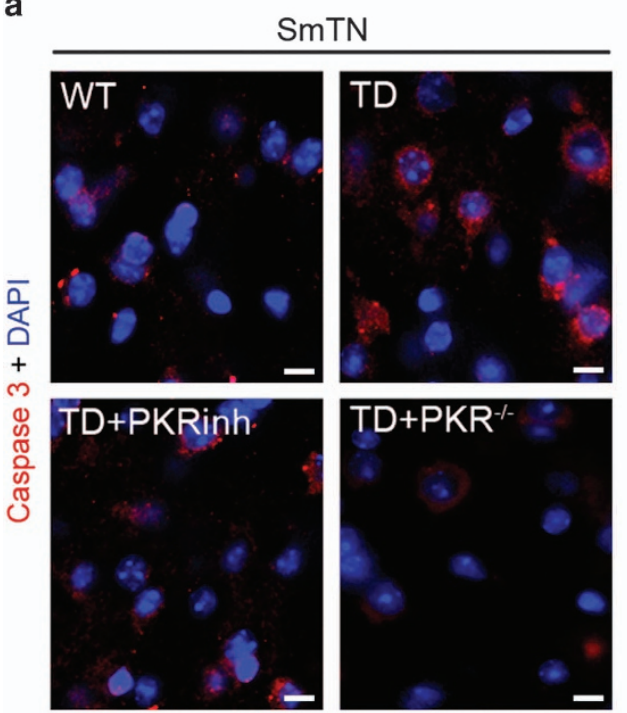

d

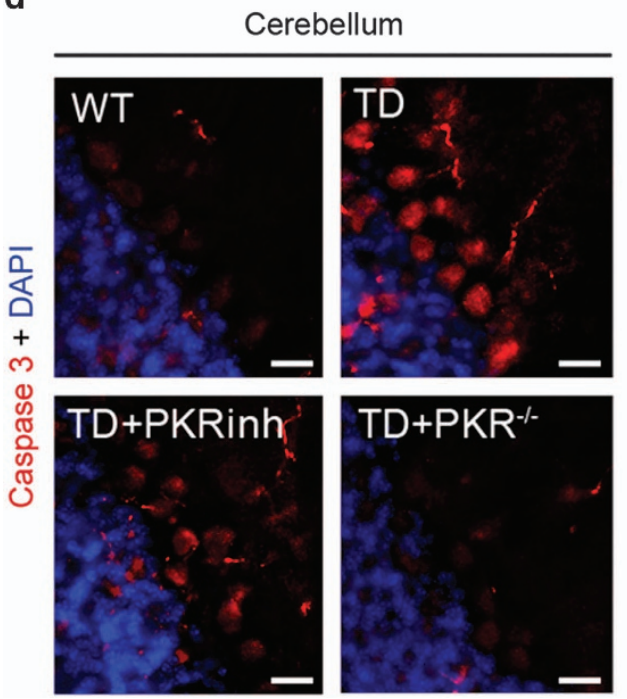

b

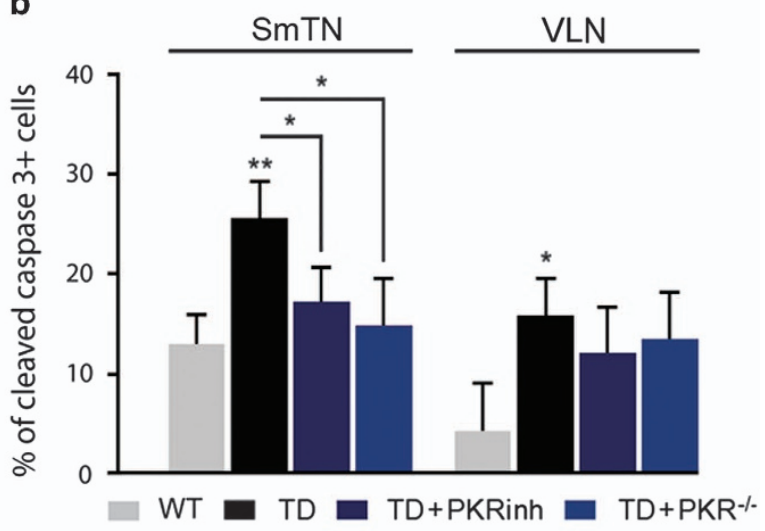

C $\mathrm{pPKR}_{\mathrm{Thr} 446}$ Caspase 3

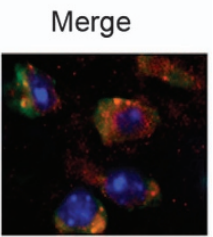

e

TD SmTN
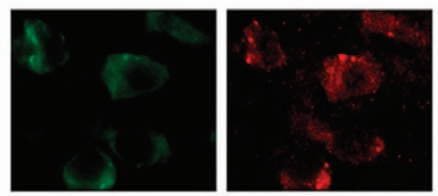

Purkinje cells

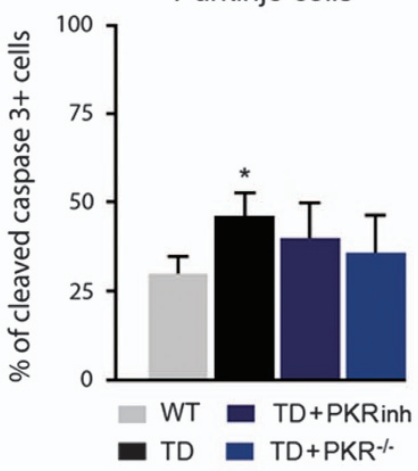

Figure 6 Immunolocalization of caspase 3 is enhanced in TD SmTN and Purkinje cells, and decreased by inhibition of PKR. (a) Double-labeling of nuclear marker DAPI (4,6diamidino-2-phenylindole; blue) and caspase 3 (red) in SmTN of WT, TD, TD+PKRinh and TD+PKR ${ }^{-1}$ mice. (b) The percentage of cleaved-caspase 3-positive neurons increased by TD is significantly reduced after downregulating PKR in SmTN (left) but not in VLN (right). (TD+PKRinh and TD+PKR ${ }^{-1-}$ ). (c) Confocal microscopy of double staining of caspase 3 (red)/PKR (green) performed with the Zenon Labeling Kit on coronal sections of TD submedial nuclei of the thalamus (SmTN) showing cytoplasmic colocalizations in neurons (yellow). ( $d$ and e) Caspase 3 immunolocalization in Purkinje cell layers (cell bodies and arborization) is amplified in TD models but is not reversed by downregulation of PKR. WT $(n=8)$, TD $(n=8)$ TD+PKRinh $(n=8)$ and TD+PKR ${ }^{-1-}(n=7){ }^{\star} P<0.05,{ }^{* \star} P<0.01$

proapoptotic effect of PKR activation, through triggering of a downstream caspase cascade. ${ }^{46}$ By suppressing PKR in our TD model, we probably reduce neuronal loss due to apoptosis and, consequently, the proportion of damaged neurons. This possibility is consistent with the immunohistochemical results revealing that enhanced cleaved caspase 3 levels are strongly colocalized with $\mathrm{pPKR}_{\mathrm{Thr} 446}$ and significantly reduced after PKR downregulation in the thalamus. In the cerebellum, the increase of cleaved caspase 3 detected in Purkinje cells was not associated with a reduced number of these neurons. Ten days of TD in our model may not be sufficient to observe this phenomenon, which is detected in the humans brains affected by Wernicke's encephalopathy. ${ }^{1}$ Moreover, inhibition of PKR also leads to a decrease in the number of damaged neurons marked by F-J B staining in TD SmTN and VLN.

PKR can control the inflammasome and is involved in the general process of innate immunity and inflammation. ${ }^{47}$ However, we did not detect any modifications of the levels of microglial activation or oxidative stress in TD mice pretreated with PKRinh or in $\mathrm{PKR}^{-1-}$ mice. This findings suggest that, in the TD model, PKR inhibition acts downstream of the initial abnormal pathways associated with the lack of vitamin B1 and that the neuroprotective and functional effects obtained with PKR inhibition could be more related to the lack of activation of intrinsic or extrinsic apoptotic pathways ${ }^{46}$ or by a late regulation of autophagy. ${ }^{48,49}$ 
During the past years, in vitro studies have demonstrated a role for elF2a kinases and, in particular PKR, in the translational control of BACE1 levels and in the amyloidogenic pathway. ${ }^{18-20}$ Here we demonstrate a similar role for PKR on amyloid processes in vivo. The activation of elF2 $a$ by TD is strongly colocalized with $\mathrm{pPKR}_{\mathrm{Thr} 446}$ and is reduced by PKR downregulation. In parallel, the levels of the other major stressinduced elF2 $a$ kinases, activated PERK and HRI remain

a

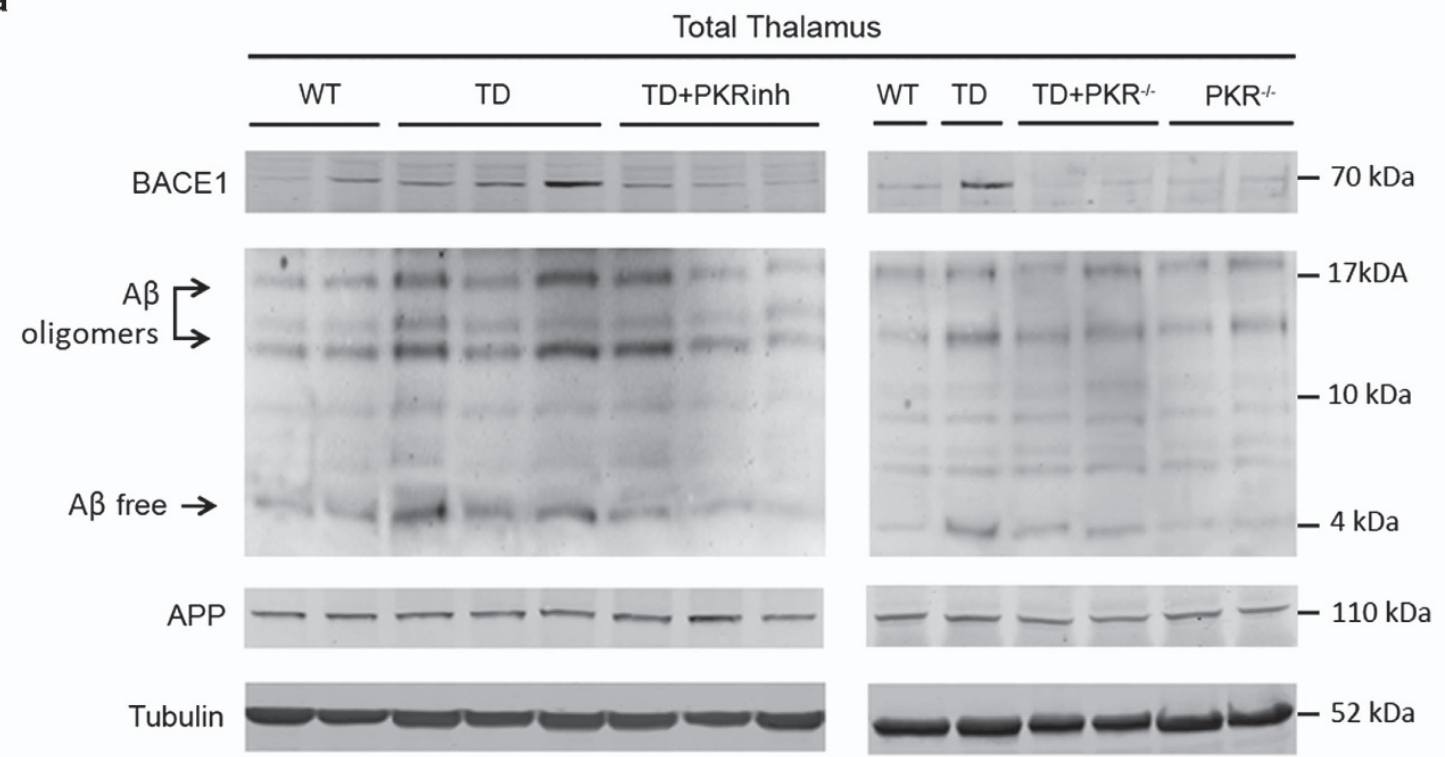

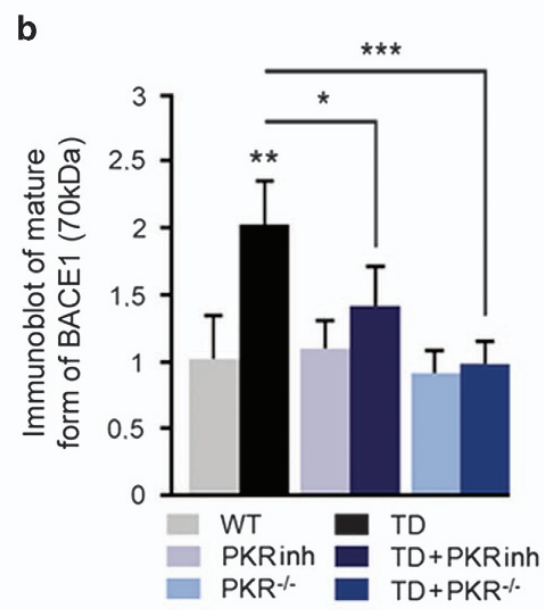

b
C

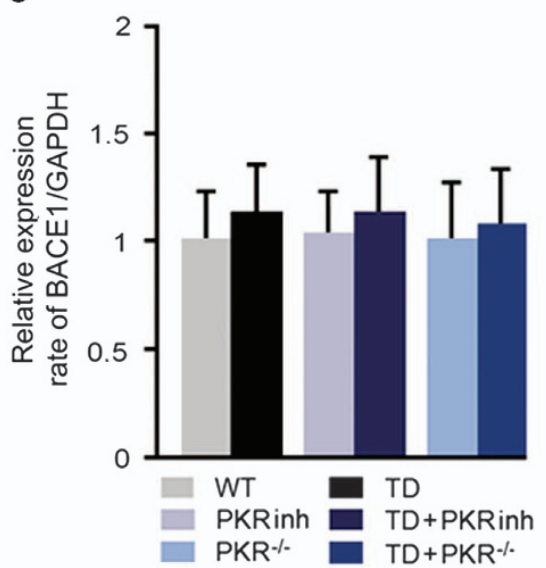

d

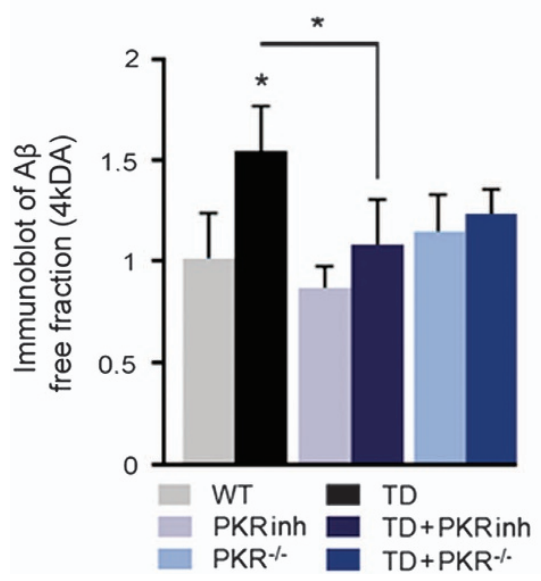

e

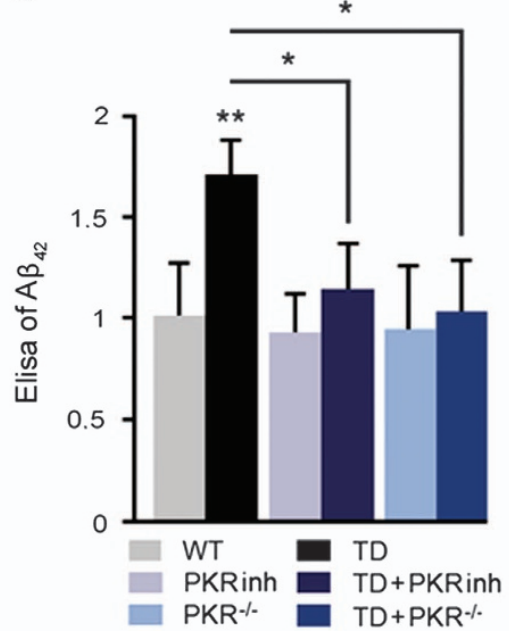

f

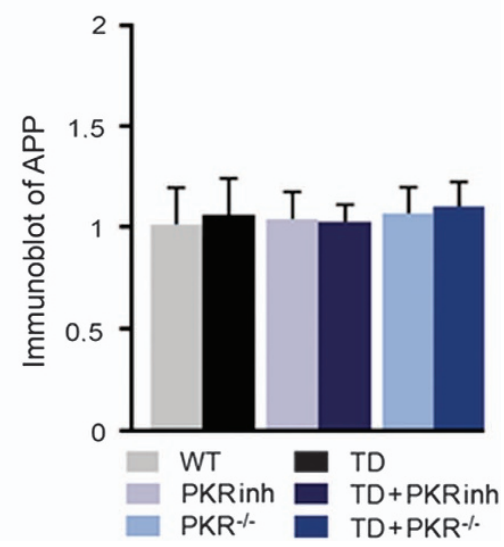


unchanged in the TD thalamus and TD cerebellum. Activated GCN2 is slightly increased only in the TD thalamus. Together the finding from $\mathrm{PKR}^{-1-}$ mice and the use of $\mathrm{PKR}$ inhibitor suggest that elF2 $a$ phosphorylation is mainly under the control of PKR in this TD model. A previous report has revealed that TD increases $\beta$-secretase activity without effect on $\gamma$-secretase activity, which leads to an increase of $A \beta$ production. ${ }^{8}$ Our results support this action on BACE1 levels and that PKR inhibition can attenuate this increase in amyloid production and BACE1 expression. A previous work has shown that OS can induce BACE1 transcription through JNK activation. ${ }^{50}$ The assessment of BACE1 mRNA levels and pJNK levels are not in favor of this possibility in TD model. Further data using JNK inhibitors in the TD model will be worth trying. Taken together, these results suggest that the increase of BACE1 levels in TD is regulated, at least in part, by a translational mechanism initiated by the PKR/elF2a pathway. Zhao et al., ${ }^{51}$ have demonstrated that pyrithiamine treatment and diet-induced TD exacerbated $A \beta$ accumulation in the brain of APP/PS1 transgenic mice. On the other hand, they also described an enhanced number of phosphorylated Tau-positive cells associated with an alteration of GSK3- $\beta$ activation. However, in our model, we have not observed any variations of Tau phosphorylation and GSK-3 $\beta$ activation, suggesting that an $A D$ brain environment might be necessary for TD-dependent phosphorylation of Tau.

The major functional finding of our study is that using $\mathrm{PKR}^{-/-}$ or exposed TD mice to specific inhibitor PKRinh significantly reduced the decline of rotarod performance in TD mice at day 8. The use of the accelerating rotarod test, a highly reproducible method to assess the motor deficit in mice, ${ }^{52}$ was initiated according to the findings obtained in previous studies on TD models. ${ }^{30}$ In our model, a progressive performance decline was detected starting at day 7 in TD mice (Figure 7) and was transiently reduced at day 8 by PKR inhibition. This effect could be related to the neuroprotective

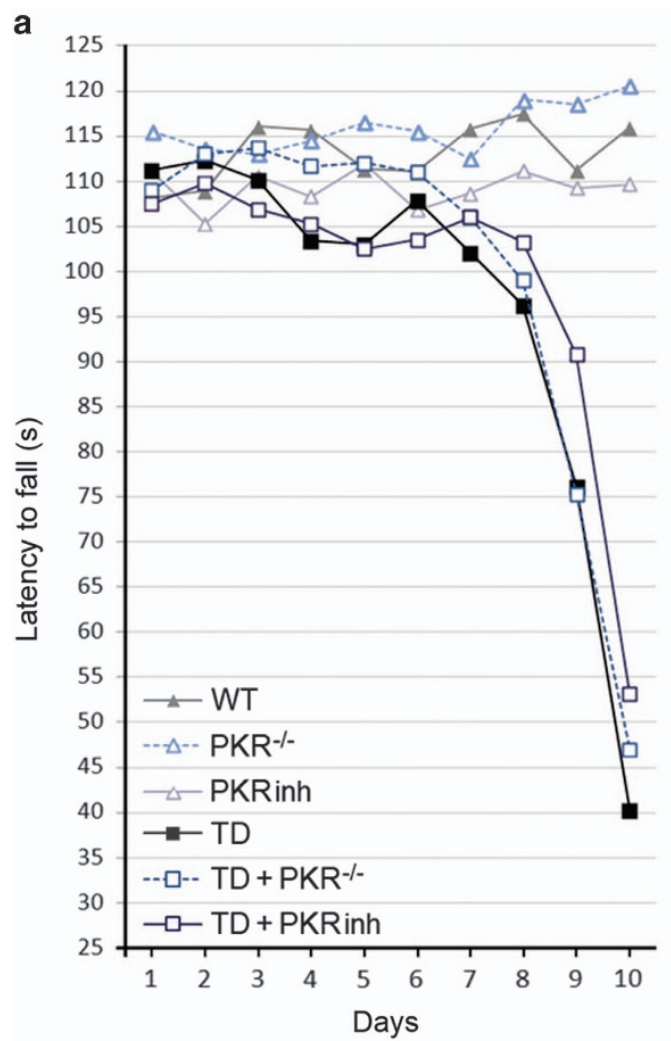

b

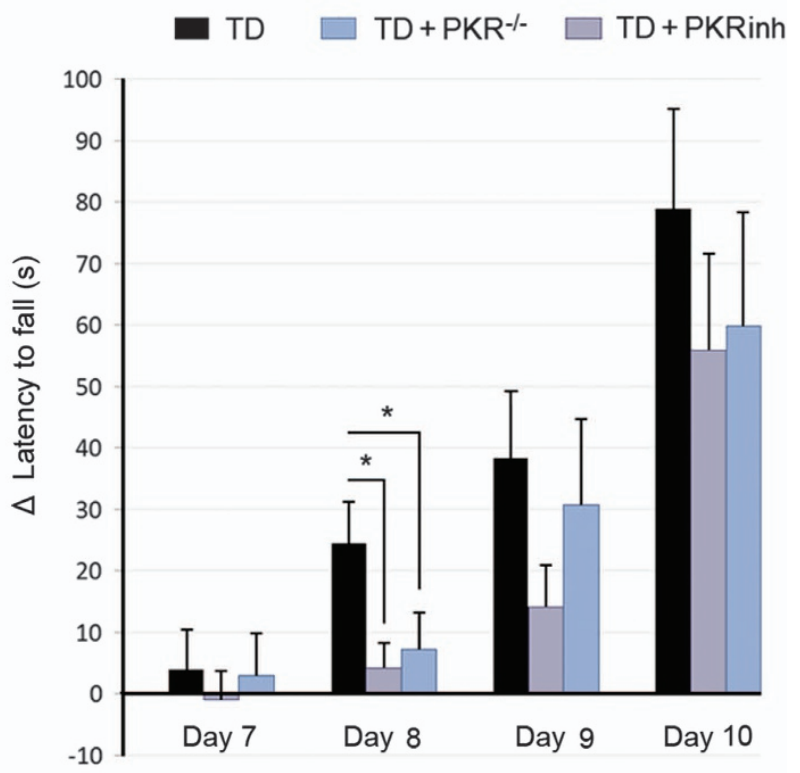

Figure 8 The rotarod motor performance impaired in TD mice is rescued after PKRinh administration or in PKR ${ }^{-1-}$ mice. (a) Diagram illustrating latency to fall measured on separate days reveals a strong decrease of motor performance in the three groups of TD mice. (b) Statistical analysis of measures for each animal of the delay between the rotarod performance between the first day of the experiment and on days 7, 8, 9 or 10. At the beginning of the decline (day 8), downregulation of PKR maintains motor performance of animals with TD. WT $(n=14)$, PKRinh $(n=14)$, PKR $^{-1-}(n=12)$ TD $(n=14)$, TD+PKRinh $(n=14)$ and TD+PKR ${ }^{-1-}(n=12) .{ }^{*} P<0.05$

Figure 7 Inhibition of PKR-elF2 $\alpha$ pathway by PKRinh or in $\mathrm{PKR}^{-1-}$ mice decreases BACE1 levels and A $\beta$ (Amyloid $\beta$ ) production. (a) Immunoblot on thalamus extracts and quantification of (b) BACE1, (d) A $\beta$ oligomers and (f) APP. The blots show that TD induces BACE1 maturation and A $\beta$ production without altering APP levels. PKR inhibition partially reduced the effects of TD. WT $(n=8)$, PKRinh $(n=8), \operatorname{PKR}^{-1-}(n=7) \operatorname{TD}(n=8)$, TD+PKRinh $(n=8)$ and TD+PKR ${ }^{-l-}(n=7)$. (c) Transcriptional activity on BACE1 is not modified in the TD thalamus. Effect of TD on BACE1 mRNA levels is assessed with quantitative reverse transcriptase-PCR. BACE1 mRNA levels were normalized to GAPDH (glyceraldehyde 3-phosphate dehydrogenase) mRNA levels. WT $(n=6)$, PKRinh $(n=5), \operatorname{PKR}^{-1-}(n=5)$ TD $(n=6)$, TD+PKRinh $(n=5)$ and TD+PKR ${ }^{-l-}(n=5)$. (e) The TDdependent increase of $A \beta_{1-42}$ peptide was confirmed by a sandwich enzyme-linked immunosorbent assay (ELISA) method and is expressed as means \pm S.E.M. A $\beta_{1-42}$. The values from TD mice are expressed relative to the values from WT mice that were set to '1'. Immunoblots and ELISA were both performed on six different groups of mice: WT $(n=8)$, PKRinh ( $n=8), \mathrm{PKR}^{-1-}(n=7)$ TD $(n=8)$, TD+PKRinh $(n=8)$, and TD+PKR ${ }^{-1-}(n=7) .{ }^{*} P<0.05,{ }^{* \star} P<0.01,{ }^{* \star *} P<0.001$ 
effect of PKR inhibition in the thalamus and Purkinje cells and could be explained in several ways. (i) Neuronal loss occurs in the SmTN, which is a part of VPL and VLN of the thalamus. VLN serves as a central integrative functional division in the thalamic nuclei for motor control, receiving inputs from the cerebellum, striatum and cortex. ${ }^{53}$ (ii) Biochemical abnormalities of the PKR, elF2 $a$ and caspase 3 in Purkinje cells, which are known to regulate and coordinate motor movements. Further electrophysiological studies analyzing Purkinje cells in TD model will be needed in the future. The strong and global imbalance of the physiological state of TD animals, as illustrated by the dramatic weight loss observed in all TD mice (with or without PKR suppression) could explain this lack of motor effect of PKR downregulation at days 9 and 10 of TD. Other motor performance tests carried out at the beginning of the decline could strengthen this hypothesis. Moreover, we cannot exclude that a part of the progressive motor impairment observed in our model could be due to metabolic changes induced by TD, in particular heart damage.

In conclusion, our results demonstrate that in vivo inhibition of PKR can allow neuroprotection and functional improvement in a TD model of neurodegeneration. In addition, PKR can modulate the in vivo production of $A \beta$. It is known that $P K R$ is activated in the AD brains and other human neurodegenerative disorders ${ }^{32,54}$ and that activated PKR is increased in the CSF of AD patients. ${ }^{15}$ In the future, pharmacological inhibition of PKR might therefore represent a valid target to slow neurodegeneration in several human diseases.

\section{Materials and Methods}

Mice. All animal experiments in this study were performed in accordance with the guidelines of the French Agriculture and Forestry Ministry for handling animals (decree 87849, license A75-05-22). PKR knockout $\left(\mathrm{PKR}^{-l-}\right.$ ) mice were obtained by disruption of the Pkr gene introduced in embryonic stem cells, which were injected into C57BL/6 blastocysts. The chimeric mice were bred to C57BL/6 mice and the progeny homozygous for the disrupted allele, as previously published. ${ }^{28}$

TD was induced in 3-month-old C57BL/6 WT and PKR ${ }^{-1-}$ mice, following a previously described protocol. ${ }^{43,45}$ Briefly, mice were housed in a controlled environment (one mouse/cage at $23{ }^{\circ} \mathrm{C}$ and $53 \%$ humidity). The animals were fed for 10 days with either a control diet (Safe, Augy, France) or a thiamine-deficient diet (Safe) ad libitum. TD animals additionally received a daily intraperitoneal injection of a thiamine pyrophosphokinase inhibitor, ${ }^{55}$ pyrithiamine hydrobromide (Sigma, St. Louis, MO, USA; $0.5 \mathrm{mg} / \mathrm{kg}$ body weight) while littermate control animals were injected with saline. Body weights were measured one time per day from days 0 to 10 .

For brain preparation, mice were anaesthetized with pentobarbital $(40 \mathrm{mg} / \mathrm{kg}$, i.p.) and received an intracardial perfusion with cold PBS. Brains were removed and dissected on ice and then placed in $4 \%(\mathrm{w} / \mathrm{v})$ paraformaldehyde in PBS for immunohistochemistry or immediately frozen in liquid nitrogen for immunoblotting or quantitative RT-PCR.

Pharmacological inhibition of PKR. An inhibitor of PKR activation, with IC50 value of $2 \mathrm{nM}$ (Reaction Biology Corporation, Malvern, PA, USA) was provided by Sanofi (Chilly-Mazarin, France) and administered daily by oral gavage $(30 \mathrm{mg} / \mathrm{kg})$. The IC50 values for the other elF2 $\alpha$ kinases are $14 \mathrm{nM}$ for GCN2, $1030 \mathrm{nM}$ for PERK and $1410 \mathrm{nM}$ for HRI. The first administration of PKR inhibitor started one day before the beginning of the TD diet.

Rotarod performance. The rotarod apparatus (Columbus Instruments, Columbus, $\mathrm{OH}, \mathrm{USA}$ ) was used to evaluate the motor coordination and balance of rodents and is especially sensitive in detecting cerebellar dysfunction. Mice were trained for 2 consecutive days to become acquainted with the rotarod apparatus. Motor performances were assessed in WT and PKR ${ }^{-1-}$ mice from days 1 to 10 , with an acceleration range of 4-40 r.p.m. in $5 \mathrm{~min}$. The latency to fall off the rotating rod per rotation speed level was recorded as a measure of motor function.
Immunoblot analyses and ELISA. Thalamus, cerebellum, cortices, hippocampi and gastrocnemius muscles were homogenized and sonicated in a radio immune precipitation assay buffer containing $25 \mathrm{mM} \beta$-glycerophosphate, $50 \mathrm{mM}$ sodium fluoride, $2 \mathrm{mM}$ sodium pyrophosphate, protease inhibitor cocktail (Roche, Penzberg, Germany), $1 \mathrm{mM}$ Sodium orthovanadate and $0.1 \mathrm{mM}$ calyculin (Sigma) as phosphatase inhibitors. They were centrifuged at $20000 \times \mathrm{g}$ for $10 \mathrm{~min}$. The protein concentration was determined with the Micro BCA Protein Assay Reagent Kit (Thermo scientific, Cergy-Pontoise, France) using the manufacturer's protocol. Protein samples (25-40 $\mu \mathrm{g}$ for each samples) were separated on gradient NuPAGE Bis-Tris gels (Invitrogen, Carlsbad, CA, USA) and then electroblotted onto nitrocellulose membranes (GE Healthcare, Chalfont St. Giles, UK) in $25 \mathrm{mM}$ Tris, (pH 8.3), $200 \mathrm{mM}$ glycine and $20 \%$ ethanol. After protein transfer, the membranes were blocked in 5\% milk in TBS and then incubated with primary antibody.

The following primary antibodies were used in immunoblots: mouse anti-Amyloid $\beta$ (Millipore, Billerica, MA, USA), rabbit anti-BACE1 (Santa Cruz, Danvers, MA, USA), mouse anti-phosphorylated GSK-3 $\beta_{\text {Tyr216 }}$ (pGSK- $3 \beta_{\text {Tyr216 }}$ ) (BD Transduction Laboratories, San Jose, CA, USA), rabbit anti-pGSK- $3 \beta_{\text {Ser }}$ (Cell Signaling, Beverly, MA, USA), mouse anti-GSK-3 $\beta$ (Santa Cruz), anti-phosphorylated JNK Thr183/Tyr185

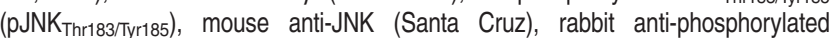
$\mathrm{PKR}_{\text {Thr446 }}\left(\mathrm{pPKR} \mathrm{R}_{\text {Thr446 }}\right.$ ) (Santa Cruz), rabbit anti-PKR (Santa Cruz), goat antiPACT/RAX (Santa Cruz), rabbit anti-phosphorylated PERK Thr981 $_{\text {(pPERK }}$ Thro81 ) (Santa Cruz), rabbit anti-PERK (Santa Cruz), rabbit anti-phosphorylated elF2 $\alpha_{\text {Ser51 }}$ (pelF2 $\left.\alpha_{\text {Ser } 51}\right) \quad$ (Cell Signaling), rabbit anti-elF2 $\alpha$ (Cell Signaling), rabbit anti-phosphorylated GCN2Thr899 (pGCN2Thr899) (Abcam, Cambridge, UK), rabbit anti-GCN2 (Cell Signaling), rabbit anti-HRI (Abcam), mouse AT8 (Ser202) (Innogenetics, Ghent, Belgium), mouse AT100 (Ser212/Thr214) (Thermo Scientific, Cergy Pontoise, France), mouse AT180 (Thr231/Ser235) (Thermo Scientific), mouse anti-Tau (Thermo Scientific), and mouse anti-Tubulin (Santa Cruz).

IR Dye 700DX conjugated anti-mouse IgG, IR Dye 800CW conjugated anti-goat IgG and IR Dye $800 \mathrm{CW}$ conjugated anti-rabbit IgG (Rockland Immunochemical Inc., Gilbertsville, PA, USA) were used as secondary antibodies. Bound proteins were visualized with the Odyssey Imaging System (Li-Cor Biosciences, Lincoln, NE, USA) and quantified with the Multigauge software (Fuij Film, Tokyo, Japan). ELISA was used to assess the $A \beta_{1-42}$ levels in thalamus samples. Frozen extracts were centrifuged, and the soluble supernatant fractions were collected. The insoluble materials were then dissolved with lysis buffer containing $8 \%$ SDS, urea and $5 \mathrm{mM}$ EDTA. $A \beta$ levels were quantified using the mouse $A \beta_{1-42}$ ELISA Kit (Invitrogen) following the manufacturer's instructions. The absorbance was read at $450 \mathrm{~nm}$ using a 96-well plate reader, and $\mathrm{A} \beta$ levels were calculated from a standard curve.

F-J B histofluorescence. F-J B (a high-affinity fluorescent marker for the localization of neuronal degeneration) (Millipore) staining was carried out according to the method described in a previous study. ${ }^{56}$ In brief, the sections were first immersed in a solution containing $1 \%$ sodium hydroxide in $80 \%$ alcohol. They were then incubated in a solution of $0.06 \%$ potassium permanganate and transferred to a $0.0004 \%$ F-J B staining solution. With this method, neurons that undergo degeneration brightly fluoresce in comparison to the background.

Immunohistofluorescence and confocal imaging. The other hemibrain from each mouse was sagitally sectioned on a cryostat apparatus at $10 \mu \mathrm{m}$. Sections were processed for immunohistofluorescence; blocking solution was PBS (phosphate buffered saline) $/ 0.25 \%$ gelatin $/ 5 \%$ normal donkey serum $/ 0.3 \%$ Triton. Primary antibodies and secondary donkey antibodies were incubated at $4{ }^{\circ} \mathrm{C}$ for $24 \mathrm{~h}$ and at $\mathrm{RT}$ for $2 \mathrm{~h}$, respectively, in PBS $/ 0.125 \%$ gelatin $/ 0.3 \%$ Triton. The primary antibodies used for immunofluorescence were as follows: rabbit anti-pPKR Thr 446 (Sigma), rabbit anti-pelF2 $\alpha_{\text {Ser51 }}$ (Cell Signaling), rabbit anti-caspase 3 active fragment (BD Bioscience, San Jose, CA, USA), mouse anti-NeuN (Millipore), rabbit anti-MDA (Abcam), and rabbit anti-ionized binding molecule adaptor 1 (Iba1) (Wako, Osaka, Japan). Secondary antibodies were donkey anti-mouse Alexa Fluor 488 (Invitrogen) or donkey anti-rabbit Cy3 (Jackson Laboratory, Bar Harbor, ME, USA). For double confocal immunohistochemistry with antibodies from the same species, we used labeled Fab techniques. This approach need to label individually with the Zenon Kit (Sigma) one of the primary antibodies with fluorescent labeled-Fab, according to manufacturer's protocol.

Standard epifluorescence images were acquired on a Leica DMRD microscope using a high-resolution camera (Coolsnap HQ, Roper Scientific, Sarasota, FL, USA). Confocal imaging was performed using a Leica SP2 confocal microscope (Leica Microsystems, Solms, Germany). The Metamorph software (Roper Scientific) was used for image acquisition. 
Counting of all the positive cells for pPKR, pelF2 $\alpha$, caspase 3, MDA, F-L B and NeuN were performed with the NIH ImageJ software (NIH Image, Bethesda, MD, USA), as previously described. ${ }^{57} \mathrm{DAPI}$ and the cyanine 3 or alexa 488 pictures were both background corrected using the rolling ball method. A threshold was then chosen using the 'Auto threshold' function of ImageJ. The distinct phenotypes of IBA1-positive microglial cells were blindly evaluated by manual counting and classified into three groups: 'amoeboid', 'ramified', and 'intermediate' (also referred to as 'unclassified').

Quantitative RT-PCR. Total RNA was isolated using the TRIzol reagent (Invitrogen) from SH-SY5Y cells. SuperScript II Reverse Transcriptase Kit (Invitrogen) with random decamer priming was used to synthesize the first-strand CDNA from samples with an equal amount of total RNA $(1 \mu \mathrm{g})$, according to the manufacturer's instructions. CDNA samples were forwarded to amplification with specific primers for BACE1 and GAPDH using SYBR Green Technology (Invitrogen) and the Stratagene Mx3005P PCR cycler (Agilent Technologies, Massy, France). Human BACE1 primers (forward 5'-GCAGGGCTACTACGTGGAGA-3' and reverse 5'-GTATCCACCAGGATGTTGAGC-3'), human GAPDH primers, (forward 5'-AATCC CA;TCACCATCTTCC- $3^{\prime}$ and reverse $5^{\prime}$-GGACTCCACGACGTACTCA- $3^{\prime}$ ) were used in the present studies. CDNA amplification was carried out as follows: denaturation at $94^{\circ} \mathrm{C}$ for $2 \mathrm{~min}$, followed by 35 cycles of denaturation at $94^{\circ} \mathrm{C}$ for $15 \mathrm{~s}$, primer annealing at $62{ }^{\circ} \mathrm{C}$ for $30 \mathrm{~s}$, and extension at $72{ }^{\circ} \mathrm{C}$ for $40 \mathrm{~s}$. A final extension was carried out at $72{ }^{\circ} \mathrm{C}$ for $10 \mathrm{~min}$, ending with a $4{ }^{\circ} \mathrm{C}$ hold cycle. All assays were performed in triplicate, and BACE1 and PKR mRNA levels were normalized with the expression levels of GAPDH. Relative levels and gene copy numbers were calculated using the deltaCp method, as described by Pfaff|. ${ }^{58}$

Statistical analysis. Statistical analysis was performed using GraphPad Prism 5 (GraphPad Software, Inc., La Jolla, CA, USA). Results were considered significant when $P<0.05$ using a non-parametric Mann and Whitney test.

\section{Conflict of Interest}

Professor Jacques Hugon is a consultant for Roche, Sanofi, Novartis, Xigen, Eisai and Lundbeck. Dr. Claire Paquet is a consultant for Lilly and Novartis. Dr. Julien Dumurgier is a consultant for Novartis. Dr. Patrick Bernardelli, Dr. Véronique Taupin, Dr. Thomas Rooney and Dr. Laurent Pradier are fully employed by Sanofi. The remaining authors declare no conflict of interest.

Acknowledgements. This work was supported by INSERM, Sanofi and APHP. We thank Mariko Taga, Dominique Briet, Clarisse Pace, Silvina Diaz and Cedric Mombereau for their technical help.

1. Baker KG, Harding AJ, Halliday GM, Kril JJ, Harper CG. Neuronal loss in functional zones of the cerebellum of chronic alcoholics with and without Wernicke's encephalopathy. Neuroscience 1999; 91: 429-438.

2. Chornyy S, Parkhomenko J, Chorna N. Thiamine deficiency caused by thiamine antagonists triggers upregulation of apoptosis inducing factor gene expression and leads to caspase 3-mediated apoptosis in neuronally differentiated rat PC-12 cells. Acta Biochim Pol 2007; 54: 315-322.

3. Calingasan NY, Huang PL, Chun HS, Fabian A, Gibson GE. Vascular factors are critical in selective neuronal loss in an animal model of impaired oxidative metabolism. J Neuropathol Exp Neurol 2000; 59: 207-217.

4. Karuppagounder SS, Shi Q, Xu H, Gibson GE. Changes in inflammatory processes associated with selective vulnerability following mild impairment of oxidative metabolism. Neurobiol Dis 2007; 26: 353-362.

5. Ke ZJ, Gibson GE. Selective response of various brain cell types during neurodegeneration induced by mild impairment of oxidative metabolism. Neurochem Int 2004; 45: 361-369.

6. Heroux M, Raghavendra Rao VL, Lavoie J, Richardson JS, Butterworth RF. Alterations of thiamine phosphorylation and of thiamine-dependent enzymes in Alzheimer's disease. Metab Brain Dis 1996; 11: 81-88.

7. Karuppagounder SS, $\mathrm{Xu} \mathrm{H}$, Shi Q, Chen LH, Pedrini S, Pechman D et al. Thiamine deficiency induces oxidative stress and exacerbates the plaque pathology in Alzheimer's mouse model. Neurobiol Aging 2009; 30: 1587-1600.

8. Zhang Q, Yang G, Li W, Fan Z, Sun A, Luo J et al. Thiamine deficiency increases beta-secretase activity and accumulation of beta-amyloid peptides. Neurobiol Aging 2011; 32: 42-53.

9. Dever TE. Gene-specific regulation by general translation factors. Cell 2002; 108: 545-556.
10. Proud CG. elF2 and the control of cell physiology. Semin Cell Dev Biol 2005; 16: 3-12.

11. Der SD, Yang YL, Weissmann C, Williams BR. A double-stranded RNA-activated protein kinase-dependent pathway mediating stress-induced apoptosis. Proc Natl Acad Sci USA 1997; 94: 3279-3283.

12. Pyo CW, Lee SH, Choi SY. Oxidative stress induces PKR-dependent apoptosis via IFNgamma activation signaling in Jurkat T cells. Biochem Biophys Res Commun 2008; 377 : 1001-1006.

13. Chang RC, Suen KC, Ma CH, Elyaman W, Ng HK, Hugon J. Involvement of double-stranded RNA-dependent protein kinase and phosphorylation of eukaryotic initiation factor-2alpha in neuronal degeneration. J Neurochem 2002; 83: 1215-1225.

14. Dumurgier J, Mouton-Liger F, Lapalus $\mathrm{P}$, Prevot M, Laplanche JL, Hugon J et al. Cerebrospinal fluid PKR level predicts cognitive decline in Alzheimer's disease. PLoS One 2013; 8: e53587.

15. Mouton-Liger F, Paquet C, Dumurgier J, Lapalus P, Gray F, Laplanche JL et al. Increased cerebrospinal fluid levels of double-stranded RNA-dependant protein kinase in Alzheimer's disease. Biol Psychiatry 2012; 71: 829-835.

16. Peidis P, Papadakis Al, Muaddi H, Richard S, Koromilas AE. Doxorubicin bypasses the cytoprotective effects of elF2alpha phosphorylation and promotes PKR-mediated cell death. Cell Death Differ 2010; 18: 145-154.

17. Bose A, Mouton-Liger F, Paquet C, Mazot P, Vigny M, Gray F et al. Modulation of tau phosphorylation by the kinase PKR: implications in Alzheimer's disease. Brain Pathol 2011; 21: 189-200.

18. III-Raga G, Palomer E, Wozniak MA, Ramos-Fernandez E, Bosch-Morato M, Tajes M et al. Activation of PKR causes amyloid ss-peptide accumulation via de-repression of BACE1 expression. PLoS One 2012; 6: e21456.

19. Mouton-Liger F, Paquet C, Dumurgier J, Bouras C, Pradier L, Gray F et al. Oxidative stress increases BACE1 protein levels through activation of the PKR-elF2 $\alpha$ pathway. Biochim Biophys Acta 2012; 1822: 885-896.

20. O'Connor T, Sadleir KR, Maus E, Velliquette RA, Zhao J, Cole SL et al. Phosphorylation of the translation initiation factor elF2alpha increases BACE1 levels and promotes amyloidogenesis. Neuron 2008; 60: 988-1009.

21. Tajes M, III-Raga G, Palomer E, Ramos-Fernandez E, Guix FX, Bosch-Morato M et al. Nitrooxidative stress after neuronal ischemia induces protein nitrotyrosination and cell death. Oxid Med Cell Longev 2013; 2013: 826143.

22. De Pietri Tonelli D, Mihailovich M, Di Cesare A, Codazzi F, Grohovaz F, Zacchetti D. Translational regulation of BACE-1 expression in neuronal and non-neuronal cells. Nucleic Acids Res 2004; 32: 1808-1817.

23. Lammich S, Schobel S, Zimmer AK, Lichtenthaler SF, Haass C. Expression of the Alzheimer protease BACE1 is suppressed via its $5^{\prime}$-untranslated region. EMBO Rep 2004; 5 : 620-625.

24. Mihailovich M, Thermann R, Grohovaz F, Hentze MW, Zacchetti D. Complex translational regulation of BACE1 involves upstream AUGs and stimulatory elements within the 5' untranslated region. Nucleic Acids Res 2007; 35: 2975-2985.

25. Wang X, Fan Z, Wang B, Luo J, Ke ZJ. Activation of double-stranded RNA-activated protein kinase by mild impairment of oxidative metabolism in neurons. $J$ Neurochem 2007; 103: 2380-2390.

26. Zhu PJ, Huang W, Kalikulov D, Yoo JW, Placzek AN, Stoica L et al. Suppression of PKR promotes network excitability and enhanced cognition by interferon-gamma-mediated disinhibition. Cell 2011; 147: 1384-1396.

27. Paxinos G, Franklin KBJ. The Mouse Brain in Stereotaxic Coordinates. 2.. Academic Press: San Diego, CA, USA, 2001.

28. Yang YL, Reis LF, Pavlovic J, Aguzzi A, Schafer R, Kumar A et al. Deficient signaling in mice devoid of double-stranded RNA-dependent protein kinase. EMBO J 1995; 14: 6095-6106.

29. Nakamura T, Furuhashi M, Li P, Cao H, Tuncman G, Sonenberg N et al. Double-stranded RNA-dependent protein kinase links pathogen sensing with stress and metabolic homeostasis. Cell 2011; 140: 338-348.

30. Shi Q, Karuppagounder SS, Xu H, Pechman D, Chen H, Gibson GE. Responses of the mitochondrial alpha-ketoglutarate dehydrogenase complex to thiamine deficiency may contribute to regional selective vulnerability. Neurochem Int 2007; 50: 921-931.

31. Garcia MA, Meurs EF, Esteban M. The dsRNA protein kinase PKR: virus and cell control. Biochimie 2007; 89: 799-811.

32. Paquet C, Bose A, Polivka M, Peoc'h K, Brouland JP, Keohane C et al. Neuronal phosphorylated RNA-dependent protein kinase in Creutzfeldt-Jakob disease. J Neuropathol Exp Neurol 2009; 68: 190-198.

33. Paquet $\mathrm{C}$, Mouton-Liger $\mathrm{F}$, Meurs EF, Mazot $\mathrm{P}$, Bouras $\mathrm{C}$, Pradier $\mathrm{L}$ et al. The $\mathrm{PKR}$ activator PACT is induced by Abeta: involvement in Alzheimer's disease. Brain Pathol 2011; 22: 219-229.

34. Patel CV, Handy I, Goldsmith T, Patel RC. PACT, a stress-modulated cellular activator of interferon-induced double-stranded RNA-activated protein kinase, PKR. J Biol Chem 2000; 275: 37993-37998.

35. Chen G, Ma C, Bower KA, Ke Z, Luo J. Interaction between RAX and PKR modulates the effect of ethanol on protein synthesis and survival of neurons. $J$ Biol Chem 2006; 281: 15909-15915.

36. Lourenco MV, Clarke JR, Frozza RL, Bomfim TR, Forny-Germano L, Batista AF et al. TNF-alpha mediates PKR-dependent memory impairment and brain IRS-1 inhibition induced by Alzheimer's beta-amyloid oligomers in mice and monkeys. Cell Metab 2013; 18: 831-843. 
37. Medinas DB, Hetz C. Proteostasis impairment: at the intersection between Alzheimer's disease and diabetes. Cell Metab 2013; 18: 771-772.

38. Jiang Z, Belforte JE, Lu Y, Yabe Y, Pickel J, Smith CB et al. elF2alpha Phosphorylationdependent translation in CA1 pyramidal cells impairs hippocampal memory consolidation without affecting general translation. J Neurosci 2010; 30: 2582-2594.

39. Chang RC, Wong AK, Ng HK, Hugon J. Phosphorylation of eukaryotic initiation factor-2alpha (elF2alpha) is associated with neuronal degeneration in Alzheimer's disease. Neuroreport 2002; 13: 2429-2432.

40. Page G, Rioux Bilan A, Ingrand S, Lafay-Chebassier C, Pain S, Perault Pochat MC et al. Activated double-stranded RNA-dependent protein kinase and neuronal death in models of Alzheimer's disease. Neuroscience 2006; 139: 1343-1354.

41. De Felice FG, Ferreira ST. Inflammation, defective insulin signaling, and mitochondrial dysfunction as common molecular denominators connecting type 2 diabetes to Alzheimer disease. Diabetes 2014; 63: 2262-2272.

42. Goh KC, deVeer MJ, Williams BR. The protein kinase PKR is required for p38 MAPK activation and the innate immune response to bacterial endotoxin. EMBO J 2000; 19 : 4292-4297.

43. Calingasan NY, Chun WJ, Park LC, Uchida K, Gibson GE. Oxidative stress is associated with region-specific neuronal death during thiamine deficiency. J Neuropathol Exp Neurol 1999; 58: 946-958.

44. Ke ZJ, Calingasan NY, DeGiorgio LA, Volpe BT, Gibson GE. CD40-CD40L interactions promote neuronal death in a model of neurodegeneration due to mild impairment of oxidative metabolism. Neurochem Int 2005; 47: 204-215.

45. Ke ZJ, DeGiorgio LA, Volpe BT, Gibson GE. Reversal of thiamine deficiency-induced neurodegeneration. J Neuropathol Exp Neurol 2003; 62: 195-207.

46. Garcia MA, Gil J, Ventoso I, Guerra S, Domingo E, Rivas C et al. Impact of protein kinase PKR in cell biology: from antiviral to antiproliferative action. Microbiol Mol Biol Rev 2006; 70 : 1032-1060.

47. Heneka MT, Kummer MP, Stutz A, Delekate A, Schwartz S, Vieira-Saecker A et al. NLRP3 is activated in Alzheimer's disease and contributes to pathology in APP/PS1 mice. Nature 2013; 493: 674-678.

48. Meng $Y$, Yong $Y$, Yang G, Ding $H$, Fan Z, Tang $Y$ et al. Autophagy alleviates neurodegeneration caused by mild impairment of oxidative metabolism. $J$ Neurochem 2013; 126: 805-818.

49. Shen S, Niso-Santano M, Adjemian S, Takehara T, Malik SA, Minoux $\mathrm{H}$ et al. Cytoplasmic STAT3 represses autophagy by inhibiting PKR activity. Mol Cell 2012; 48: 667-680.
50. Tamagno E, Bardini $P$, Obbili A, Vitali A, Borghi R, Zaccheo $D$ et al. Oxidative stress increases expression and activity of BACE in NT2 neurons. Neurobiol Dis 2002; 10: 279-288.

51. Zhao J, Sun X, Yu Z, Pan X, Gu F, Chen J et al. Exposure to pyrithiamine increases $\beta$-amyloid accumulation, Tau hyperphosphorylation, and glycogen synthase kinase-3 activity in the brain. Neurotox Res 2011; 19: 575-583.

52. Jones BJ, Roberts DJ. The quantiative measurement of motor inco-ordination in naive mice using an acelerating rotarod. J Pharm Pharmacol 1968; 20: 302-304.

53. Tlamsa AP, Brumberg JC. Organization and morphology of thalamocortical neurons of mouse ventral lateral thalamus. Somatosens Mot Res 2010; 27: 34-43.

54. Bando Y, Onuki R, Katayama T, Manabe T, Kudo T, Taira K et al. Double-strand RNA dependent protein kinase (PKR) is involved in the extrastriatal degeneration in Parkinson's disease and Huntington's disease. Neurochem Int 2005; 46: 11-18.

55. Liu JY, Timm DE, Hurley TD. Pyrithiamine as a substrate for thiamine pyrophosphokinase. J Biol Chem 2006; 281: 6601-6607.

56. Schmued LC, Hopkins KJ. Fluoro-Jade B: a high affinity fluorescent marker for the localization of neuronal degeneration. Brain Res 2000; 874: 123-130.

57. Schmuck M, Temme T, Heinz S, Baksmeier C, Mosig A, Colomina MT et al. Automatic counting and positioning of 5-bromo-2-deoxyuridine (BrdU) positive cells in cortical layers of rat brain slices. Neurotoxicology 2014; 43: 127-133.

58. Pfaffl MW. A new mathematical model for relative quantification in real-time RT-PCR. Nucleic Acids Res 2001; 29: e45.

(i) Cell Death and Disease is an open-access journal published by Nature Publishing Group. This work is licensed under a Creative Commons Attribution 4.0 International Licence. The images or other third party material in this article are included in the article's Creative Commons licence, unless indicated otherwise in the credit line; if the material is not included under the Creative Commons licence, users will need to obtain permission from the licence holder to reproduce the material. To view a copy of this licence, visit http://creativecommons.org/licenses/by/4.0

Supplementary Information accompanies this paper on Cell Death and Disease website (http://www.nature.com/cddis) 